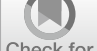

Check for

updates

Cite as

Nano-Micro Lett.

(2020) 12:16

Received: 30 October 2019

Accepted: 3 December 2019

Published online: 4 January 2020

(C) The Author(s) 2020

\section{Graphitic Carbon Quantum Dots Modified Nickel Cobalt Sulfide as Cathode Materials for Alkaline Aqueous Batteries}

Yirong Zhu ${ }^{1}$, Jingying $\mathrm{Li}^{1}$, Xiaoru Yun ${ }^{1}$, Ganggang Zhao ${ }^{2}$, Peng $\mathrm{Ge}^{2}$, Guoqiang Zou ${ }^{2}$, Yong $\mathrm{Liu}^{3}$, Hongshuai $\mathrm{Hou}^{2}{ }^{凶}$, Xiaobo $\mathrm{Ji}^{2}$

$\triangle$ Hongshuai Hou, hs-hou@csu.edu.cn

1 College of Metallurgy and Material Engineering, Hunan University of Technology, Zhuzhou 412007, People's Republic of China

2 College of Chemistry and Chemical Engineering, Central South University, Changsha 410083, People's Republic of China

3 State Key Lab of Powder Metallurgy, Central South University, Changsha 410083, People's Republic of China

\title{
HIGHLIGHTS
}

- The scalable graphitic carbon quantum dots (CQDs) are obtained with a high yield of more than $50 \%$.

- The CQDs are utilized to synthesize novel NS-CQDs/ $\mathrm{NiCo}_{2} \mathrm{~S}_{4}$ composite which shows enhanced electrochemical properties.

- The assembled novel alkaline aqueous battery delivers superior electrochemical performances.

\begin{abstract}
Carbon quantum dots (CQDs) as a new class of emerging materials have gradually drawn researchers' concern in recent years. In this work, the graphitic CQDs are prepared through a scalable approach, achieving a high yield with more than 50\%. The obtained CQDs are further used as structure-directing and conductive agents to synthesize novel N,S-CQDs/ $\mathrm{NiCo}_{2} \mathrm{~S}_{4}$ composite cathode materials, manifesting the enhanced electrochemical properties resulted from the synergistic effect of highly conductive $\mathrm{N}, \mathrm{S}$-codoped CQDs offering fast electronic transport and unique micro-/nanostructured $\mathrm{NiCo}_{2} \mathrm{~S}_{4}$ microspheres with Faradaic redox characteristic contributing large capacity. Moreover, the nitrogen-doped reduced graphene oxide $(\mathrm{N}-\mathrm{rGO}) / \mathrm{Fe}_{2} \mathrm{O}_{3}$ composite anode materials exhibit ultrahigh specific capacity as well as significantly improved rate property and cycle performance originating from the high-capacity prism-like $\mathrm{Fe}_{2} \mathrm{O}_{3}$ hexahedrons tightly wrapped by highly conductive N-rGO. A novel alkaline aqueous battery assembled by

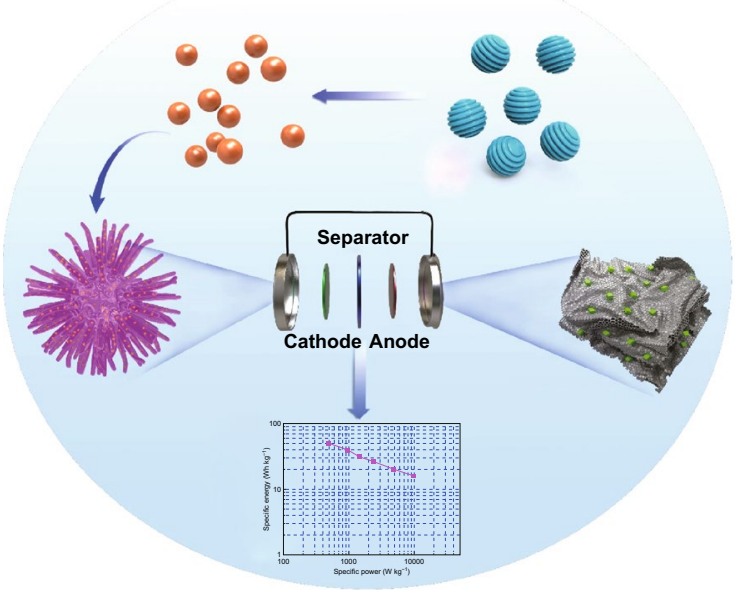
these materials displays a specific energy $\left(50.2 \mathrm{Wh} \mathrm{kg}^{-1}\right)$, ultrahigh specific power $\left(9.7 \mathrm{~kW} \mathrm{~kg}^{-1}\right)$ and excellent cycling performance with $91.5 \%$ of capacity retention at $3 \mathrm{~A} \mathrm{~g}^{-1}$ for 5000 cycles. The present research offers a valuable guidance for the exploitation of advanced energy storage devices by the rational design and selection of battery/capacitive composite materials.
\end{abstract}

KEYWORDS Energy storage; Alkaline aqueous batteries; Carbon quantum dot; Nickel cobalt sulfide 


\section{Introduction}

Carbon quantum dots (CQDs), as a novel type of zerodimensional (0D) carbon materials with ultrasmall sizes less than $10 \mathrm{~nm}$, have been extensively applied in fluorescence, bioimaging, biosensing, photocatalysis and photovoltaics owing to their unique advantages such as quantum confinement and edge effects [1-4]. In particular, the application of CQDs in energy storage has gradually attracted researchers' attention in recent years [5-7]. In the early research, the reduced carbon quantum dots ( $\mathrm{rCQDs}) / \mathrm{RuO}_{2}$ composites have been obtained as ultrafast supercapacitor electrode materials for the first time, where rCQDs are utilized as conductive agents to boost the electrical conductivity of electrode materials, enhancing the supercapacitive properties, especially rate capability [8]. Since this reported pioneering work, more researches about such CQDs-based energy storage materials as supercapacitors, lithium/sodium ion batteries and fuel cell have been explored [9-14], which indicates that these upcoming CQDs-based electrode materials present a great prospect as superior energy storage materials. Nevertheless, the utilization of CQDs as electrode materials is much less reported compared to the conventional carbon materials; hence, it shows a great potential to further explore them.

Currently, the methods for the synthesis of CQDs are usually classified into "top-down" and "bottom-up" types. The former is usually breaking down large-size carbon materials into CQDs, including arc discharge, electrochemical exfoliation, hydrothermal technique and chemical oxidation synthesis [15-18], whereas the latter is usually preparing CQDs from molecular precursors, such as combustion/ thermal decomposition method, supported synthesis and microwave pyrolysis synthetic route [19-21]. However, these approaches for the synthesis of CQDs still face major challenges, such as a low yield (usually lower than 10\%), complicated processes, poor reproducibility and electronic conductivity [1]. In our previous study, graphitic CQDs were obtained via chemical oxidation synthesis route utilizing nano-graphite powders $(\sim 30 \mathrm{~nm})$ as precursors, and a relatively low yield of less than $20 \%$ was acquired $[8,10]$. Hou et al. obtained non-graphitic CQDs through a facile and scalable solution growth method by mixing $\mathrm{NaOH}$ and acetone together, and an ultrahigh yield with gram level was achieved. However, the resulted CQDs presented low electronic conductivity, leading to the poor electrochemical properties [12]. From the perspective of practical application for energy storage electrode materials, it is crucially important to develop a scalable approach for synthesizing CQDs with a high yield, low cost and high electrical conductivity.

Besides, another major challenge for CQDs is that they are apt to aggregate and stack together, which results in a rapid decrease in their specific surface areas and kinetic behaviors, thus worsening the electrochemical properties of CQDs [22]. These obstacles above prevent their utilization as excellent energy storage electrode materials. The most effective method to solve the aggregation is to employ them as composite materials. Recently, ternary metal oxides/ sulfides have attracted extensive interests because of their higher electrical conductivity and richer electrochemical activity than those of the corresponding binary metal oxides/sulfides, which have been explored as potential cathode materials for alkaline aqueous batteries [23-28]. Among them, $\mathrm{NiCo}_{2} \mathrm{~S}_{4}$ is seen as the most prospective candidate for future utilization in such energy storage as supercapacitors and lithium ion batteries. To further enhance its comprehensive electrochemical performances, an effective way is to design various unique micro-/nanostructured $\mathrm{NiCo}_{2} \mathrm{~S}_{4}$, and the enhanced electrochemical properties have been reported by researchers in the literature [29-33]. Another good way is to introduce carbon materials to prepare the composite electrode materials, leading to the enhanced electrochemical properties to some extent. Currently, the most reported carbon materials are graphene and carbon nanotubes, demonstrating decent electrochemical properties, but their high cost seriously prevents the practical application [34, 35]. Therefore, it is very emergent to exploit novel and cheap carbon materials for the fabrication of superior composite electrode materials.

As discussed above, the scalable graphitic CQDs were first synthesized with a high yield of more than 50\% utilizing highly conductive Super P powders as precursors. Then, the CQDs were employed as both structure-directing and conductive agents to prepare new N,S-codoped CQDs-decorated urchin-like $\mathrm{NiCo}_{2} \mathrm{~S}_{4}$ microspheres for the first time. In comparison with the pure $\mathrm{NiCo}_{2} \mathrm{~S}_{4}$ electrode, the N,S-CQDs/ $\mathrm{NiCo}_{2} \mathrm{~S}_{4}$ composite electrode, when for the first time used as cathode for alkaline aqueous batteries, exhibits enhanced electrochemical properties with a high specific capacity of $124.4 \mathrm{mAh} \mathrm{g}^{-1}$ at $2 \mathrm{~A} \mathrm{~g}^{-1}$, exceptional capacity retention of $77.3 \%$ at $50 \mathrm{~A} \mathrm{~g}^{-1}$ in comparison with $2 \mathrm{~A} \mathrm{~g}^{-1}$ and excellent 
cycling property with $97.9 \%$ of initial capacity retention at $3 \mathrm{~A} \mathrm{~g}^{-1}$ for 5000 cycles. Meanwhile, the N-rGO-wrapped prism-like $\mathrm{Fe}_{2} \mathrm{O}_{3}$ hexahedrons composite anode materials are obtained, which manifest substantially enhanced electrochemical performances with an ultrahigh specific capacity (249.6 $\mathrm{mAh} \mathrm{g}^{-1}$ at $1 \mathrm{~A} \mathrm{~g}^{-1}$ ) as well as greatly enhanced rate property and cycling life compared with those of the pristine $\mathrm{Fe}_{2} \mathrm{O}_{3}$ electrode. A novel N,S-CQDs/ $/ \mathrm{NiCo}_{2} \mathrm{~S}_{4} / / \mathrm{N}-\mathrm{rGO} /$ $\mathrm{Fe}_{2} \mathrm{O}_{3}$ alkaline aqueous battery fabricated by these materials achieves a specific energy $\left(50.2 \mathrm{Wh} \mathrm{kg}^{-1}\right)$ and ultrahigh specific power $\left(9,700 \mathrm{~W} \mathrm{~kg}^{-1}\right)$ with excellent cycle property (91.5\% of capacity retention for 5000 cycles). The encouraging results display the enormous potential of the new alkaline aqueous battery as highly promising energy storage system for potentially practical applications.

\section{Experimental Section}

\subsection{Synthesis of CQDs}

CQDs were obtained by a scalable chemical oxidation approach. Super P powders (1 g, purchased from SigmaAldrich) were first added into concentrated $\mathrm{H}_{2} \mathrm{SO}_{4} / \mathrm{HNO}_{3}$ mixed solution $(80 \mathrm{~mL}, \mathrm{v} / \mathrm{v}, 3: 1)$ and then sonicated for $1 \mathrm{~h}$. The resulting mixture was refluxed for $24 \mathrm{~h}$. Subsequently, the mixture was further neutralized with $\mathrm{Na}_{2} \mathrm{CO}_{3} \cdot 10 \mathrm{H}_{2} \mathrm{O}$, and the $\mathrm{pH}$ was controlled at 7.0. After further dialysis and vacuum-drying, the final CQDs powders were obtained.

\subsection{Synthesis of $\mathrm{N}, \mathrm{S}-\mathrm{CQDs} / \mathrm{NiCo}_{2} \mathrm{~S}_{4}$ Composite Materials}

The N,S-CQDs $/ \mathrm{NiCo}_{2} \mathrm{~S}_{4}$ composite materials were synthesized by a one-step hydrothermal approach. Firstly, CQDs powders ( $22.3 \mathrm{mg}$ ) were dissolved in $\mathrm{H}_{2} \mathrm{O}$ /ethanol mixed solution $(60 \mathrm{~mL}, \mathrm{v} / \mathrm{v}, 1: 1)$ and agitated for $10 \mathrm{~min}$. Subsequently, $\mathrm{NiCl}_{2} \cdot 6 \mathrm{H}_{2} \mathrm{O}(0.06952 \mathrm{~g})$ and $\mathrm{CoCl}_{2} \cdot 6 \mathrm{H}_{2} \mathrm{O}$ $(0.13919 \mathrm{~g})$ were added into the obtained mixture and stirred for $20 \mathrm{~min}$. Then, thioacetamide $(0.13185 \mathrm{~g})$ was further introduced into the above mixture. After continual agitating for another $20 \mathrm{~min}$, the as-resulted mixed solution was transferred into a stainless steel autoclave lined with PTFE $(100 \mathrm{~mL})$ and hydrothermally treated at $180{ }^{\circ} \mathrm{C}$ for $24 \mathrm{~h}$. The products were obtained by alternate centrifuging with $\mathrm{H}_{2} \mathrm{O}$ and ethanol for three times and further vacuum-dried overnight at $70{ }^{\circ} \mathrm{C}$. For comparison, the pure $\mathrm{NiCo}_{2} \mathrm{~S}_{4}$ was synthesized by the similar method only without adding CQDs powders in this preparation process.

\subsection{Synthesis of $\mathrm{N}-\mathrm{rGO} / \mathrm{Fe}_{2} \mathrm{O}_{3}$ Composite Materials}

The N-rGO/ $\mathrm{Fe}_{2} \mathrm{O}_{3}$ composite materials were prepared by a facile hydrothermal approach. Firstly, graphite oxide (GO, $40 \mathrm{mg}$, purchased from XFNANO) was dissolved in $\mathrm{H} 2 \mathrm{O}$ solution $(30 \mathrm{~mL})$ and sonicated for $1 \mathrm{~h}$. Then, $\mathrm{FeCl} 3 \cdot 6 \mathrm{H} 2 \mathrm{O}$ $(0.5406 \mathrm{~g})$ was dissolved in $\mathrm{H} 2 \mathrm{O}$ solution $(15 \mathrm{~mL})$ and stirred for $10 \mathrm{~min}$. The as-resulted $\mathrm{FeCl}_{3}$ aqueous solution was added into the GO solution and sonicated for $30 \mathrm{~min}$. Meanwhile, urea $(0.6006 \mathrm{~g})$ was dissolved in $\mathrm{H} 2 \mathrm{O}$ solution $(15 \mathrm{~mL})$ and magnetically stirred for $10 \mathrm{~min}$. Furthermore, the resulting urea solution was slowly introduced into the above mixture under strong agitation. After stirring for $30 \mathrm{~min}$, the as-obtained mixture was transferred into a stainless steel autoclave lined with PTFE $(100 \mathrm{~mL})$ and subjected to hydrothermal reaction at $180{ }^{\circ} \mathrm{C}$ for $10 \mathrm{~h}$. Lastly, the products were obtained by alternately centrifuging with $\mathrm{H}_{2} \mathrm{O}$ and ethanol for three times and further vacuum-dried overnight at $70{ }^{\circ} \mathrm{C}$. For comparison, the pure $\mathrm{Fe}_{2} \mathrm{O}_{3}$ was synthesized by the similar method only in the absence of $\mathrm{GO}$ in this preparation process.

\subsection{Materials Characterization}

X-ray diffraction (XRD) analysis was implemented on an X-ray diffractometer (Rigaku D/max $2550 \mathrm{VB}^{+}$). Raman spectra were executed on a Raman spectrometer (Labram-010). X-ray photoelectron spectroscope (XPS) analysis was conducted on a photoelectron spectrometer (K-Alpha). FESEM images, EDS and elemental mappings were captured on a field emission scanning electron microscopy (FESEM, MIRA3). Transmission electron microscope (TEM) images, HRTEM images and SAED patterns were obtained on a transmission electron microscopy (JEM-2100F). TG curves were recorded from a thermal analysis instrument (NETZSCH STA449C). $\mathrm{N}_{2}$ adsorption/desorption isotherms were acquired on a BET specific surface area analyzer (BELSORP-miniII). 


\subsection{Electrochemical Measurements}

To fabricate the working electrodes for electrochemical tests, $70 \mathrm{wt} \%$ of electroactive material, $20 \mathrm{wt} \%$ of Super $\mathrm{P}$ and $10 \mathrm{wt} \%$ of PVDF with NMP as solvent were adequately mixed to obtain an uniform slurry. Afterward, the resulting slurry was dipped into $\mathrm{Ni}$ foam current collector, which was pretreated based on our previous work [10], and dried in a vacuum oven at $70{ }^{\circ} \mathrm{C}$ overnight. Finally, the as-fabricated electrodes were further pressed at $10 \mathrm{MPa}$. The electrochemical properties of the single electrode were conducted by employing a typical three-electrode cell with platinum foil, $\mathrm{Hg} / \mathrm{HgO}$ and $2 \mathrm{M} \mathrm{KOH}$ solution as counter electrode, reference electrode and electrolyte, respectively. The alkaline aqueous coin battery (CR 2016) was further assembled by utilizing $\mathrm{N}, \mathrm{S}-\mathrm{CQDs} / \mathrm{NiCo}_{2} \mathrm{~S}_{4}$ as cathode, $\mathrm{N}-\mathrm{rGO} / \mathrm{Fe}_{2} \mathrm{O}_{3}$ as anode, glassy fibrous material as separator and $2 \mathrm{M} \mathrm{KOH}$ solution as electrolyte. The electrochemical tests such as CV, GCD and EIS for both single electrode and alkaline aqueous device were executed on an electrochemical workstation (CHI 760E).

\section{Results and Discussion}

\subsection{Preparation Processes of the CQDs and the Composite Cathode and Anode}

The synthetic processes of the graphitic CQDs, the N,S$\mathrm{CQDs} / \mathrm{NiCo}_{2} \mathrm{~S}_{4}$ composite cathode and $\mathrm{N}-\mathrm{rGO} / \mathrm{Fe}_{2} \mathrm{O}_{3}$ composite anode are demonstrated in Fig. 1. First, the graphitic CQDs are prepared through a scalable mixedacid chemical oxidation approach using the industrialized, cheap and highly conductive Super P powders as precursors. The obtained CQDs achieve a high yield of more than $50 \%$, which is far higher than that prepared by most of previous work reported in the literature [1, $8,10,36,37]$, demonstrating the great prospect for their potentially practical application. Afterward, the resulting CQDs are further employed as structure-directing and conductive agents to prepare novel N,S-codoped CQDsdecorated urchin-like $\mathrm{NiCo}_{2} \mathrm{~S}_{4}$ microspheres composite cathode materials via a one-step hydrothermal approach, in which thioacetamide is used as precipitant to generate the $\mathrm{NiCo}_{2} \mathrm{~S}_{4}$ and codoped agent to achieve nitrogen and

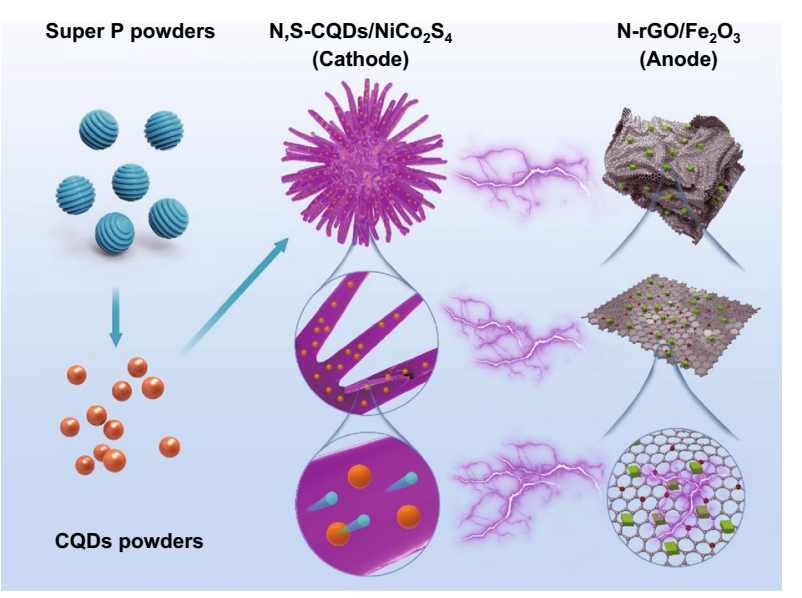

Fig. 1 Schematic illustration of the synthetic processes of the CQDs, the N,S-CQDs $/ \mathrm{NiCo}_{2} \mathrm{~S}_{4}$ composite cathode and $\mathrm{N}-\mathrm{rGO} / \mathrm{Fe}_{2} \mathrm{O}_{3}$ composite anode

sulfur codoping into the CQDs. In this process, the CQDs are not only utilized as structure-directing agents to induce the formation of nanorods-assembled urchin-like composite microsphere structure, but also served as conductive agents to improve the electrical conductivity of the composite cathode materials. Meanwhile, the $\mathrm{N}$-doped rGOwrapped prism-like $\mathrm{Fe}_{2} \mathrm{O}_{3}$ hexahedrons composite anode materials are prepared by a facile hydrothermal synthetic route, where urea serves as precipitant to generate the $\mathrm{Fe}_{2} \mathrm{O}_{3}$ and acts as doped agent to achieve nitrogen doping into the GO. The $\mathrm{Fe}_{2} \mathrm{O}_{3}$ hexahedrons are tightly wrapped by the N-rGO sheets, and the close contact between the $\mathrm{Fe}_{2} \mathrm{O}_{3}$ hexahedrons and the $\mathrm{N}$-rGO sheets can improve the electrochemical kinetic behavior and structural stability of the composite anode materials.

\subsection{Physicochemical Characterization of CQDs}

Figure 2a shows the digital photograph of the industrial Super P powders, and their FESEM images (Fig. S1) reveal that the Super P powders display nanoparticles-like morphology with a size of about $50 \mathrm{~nm}$. As observed from the digital photograph (Fig. S2a), the Super P powders are insoluble in $\mathrm{H}_{2} \mathrm{SO}_{4} / \mathrm{HNO}_{3}$ mixed solution after the treatment of sonication. However, the digital photograph (Fig. S2b) reveals that the obtained CQDs are highly soluble in $\mathrm{H}_{2} \mathrm{O}$ solution, and also the resulted CQDs aqueous solution does 
(a)

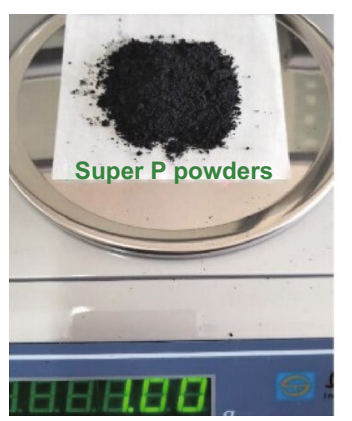

(b)

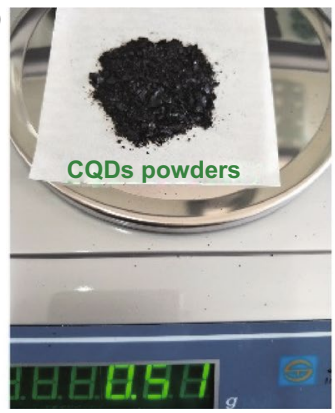

(c)
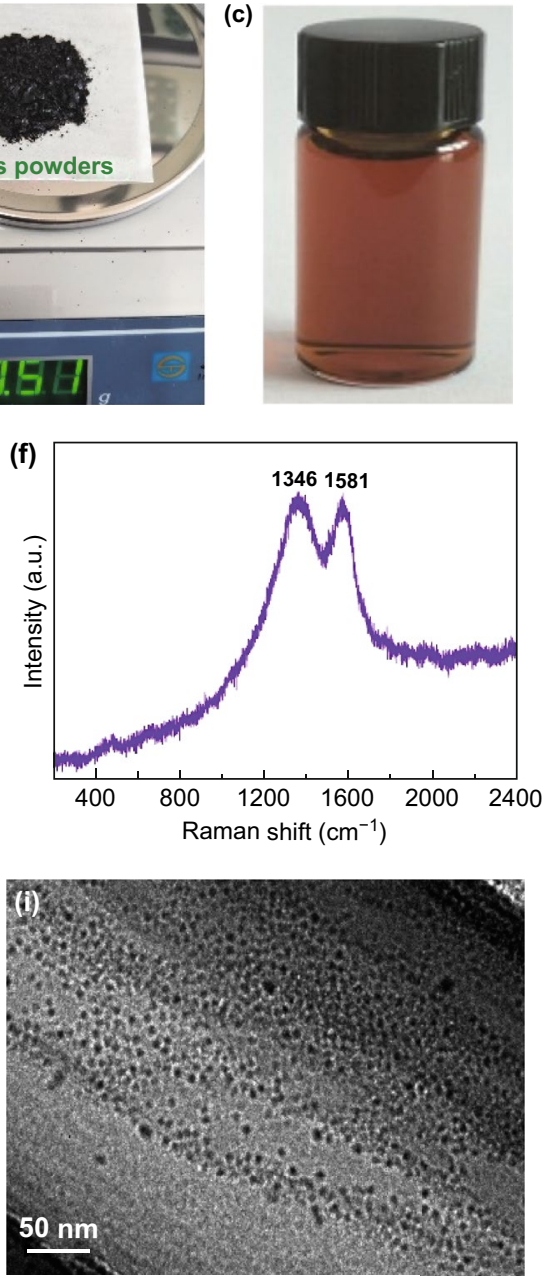

(d)
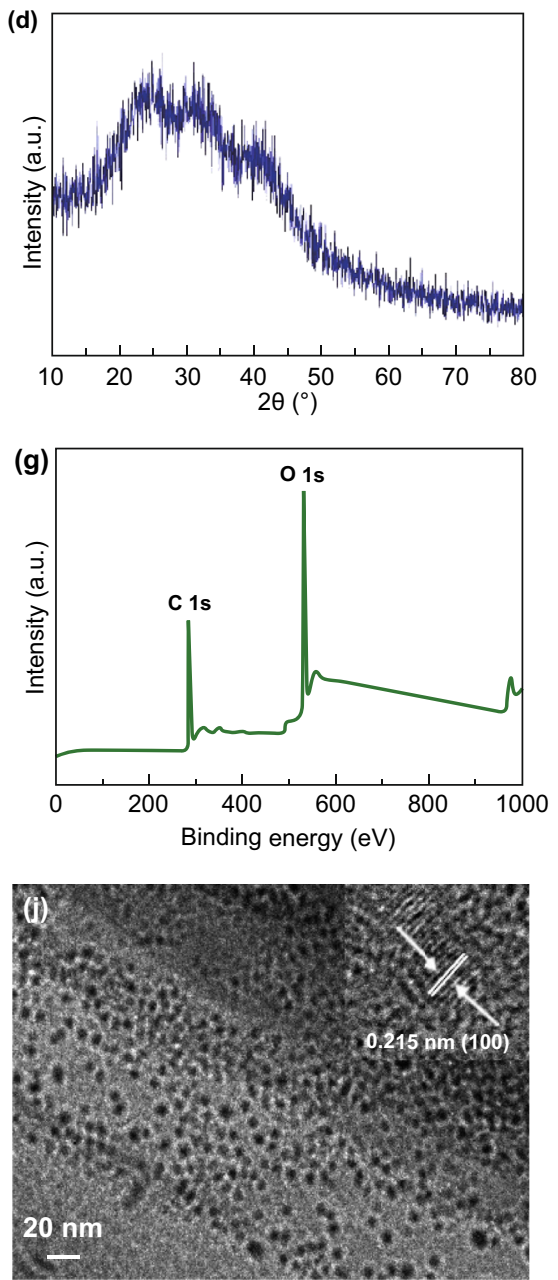

Fig. 2 Digital photograph of a Super P powders, b CQDs powders, and $\mathbf{c}$ CQDs aqueous solution with a concentration of $1 \mathrm{mg} \mathrm{mL}^{-1}$. d XRD pattern, e FTIR spectroscopy, f Raman spectroscopy, $\mathbf{g}$ XPS survey spectrum, h high-resolution C $1 \mathrm{~s}$ spectrum, $\mathbf{i}$, j TEM images and HRTEM image (inset of Fig. 2j) of CQDs

not show any change after 6 months at ambient temperature as manifested in Fig. 2c, suggesting their high stability. Figure $2 \mathrm{~b}$ is the digital photograph of the final obtained CQDs powders, and the yield is up to $51 \%$. Thus, the scalable synthesis of CQDs with a high yield, together with the advantages of employing a cheap and industrial carbon source, renders them being potential candidate electrode materials for large-scale storage application.

Figure $2 \mathrm{~d}$ illustrates the XRD pattern of CQDs, and the broad peak of CQDs at around $25^{\circ}$ corresponds to (002) plane of the disordered graphite carbon resulting from the strong acid etching [38]. Also, no other peak such as inorganic salts is observed, indicating the high purity of CQDs. FTIR spectrum (Fig. 2e) reveals that the main peaks at $3445,1720,1592,1370$ and $1252 \mathrm{~cm}^{-1}$ are well fitted to the $\mathrm{C}-\mathrm{OH}, \mathrm{C}=\mathrm{O}, \mathrm{C}=\mathrm{C}, \mathrm{C}-\mathrm{H}$ and $\mathrm{C}-\mathrm{O}-\mathrm{C}$ bonds [8, 39], respectively, and the existence of these bonds shows that the CQDs are functionalized with the abundant oxygencontaining surface groups, which is particular in favor of the construction of composite materials by the utilization of the functionalized CQDs. Raman spectroscopy (Fig. 2f) was used to further characterize the structure of CQDs. The two obvious peaks at 1346 and $1581 \mathrm{~cm}^{-1}$ belong to the D-band and G-band of CQDs, which are attributed to the disordered 
carbon and ordered graphitic structure, respectively [40]. XPS was undertaken to characterize the elemental composition and carbon bonds of CQDs, as presented in Fig. $2 \mathrm{~g}$, h. The four peaks at $284.8,286.5,288.4$ and $289.2 \mathrm{eV}$ in the spectrum of $\mathrm{C} 1 \mathrm{~s}$ (Fig. 2h) are, respectively, ascribed to the $\mathrm{C}-\mathrm{C}, \mathrm{C}-\mathrm{O}, \mathrm{C}=\mathrm{O}$ and $\mathrm{O}-\mathrm{C}=\mathrm{O}$ bonds, which accord well with FTIR analysis results [12]. Figure 2i, j exhibits the TEM images of the as-obtained CQDs, and it is clear that the as-prepared CQDs are monodisperse with the uniform distribution in the range of $5-8 \mathrm{~nm}$. As exhibited in the inset of Fig. $2 \mathrm{j}$, the HRTEM image manifests the lattice fringe of $0.215 \mathrm{~nm}$, which accords well with the (100) plane of graphitic carbon, proving the formation of graphitic CQDs.

\subsection{Physicochemical and Electrochemical Characterizations of the Cathode Materials}

The morphology and microstructure of the as-resulted N,SCQDs/ $\mathrm{NiCo}_{2} \mathrm{~S}_{4}$ composite were examined by FESEM, TEM, HRTEM, EDS and elemental mappings. As demonstrated in Fig. 3a-c, the FESEM images show that the composite presents the urchin-like microsphere structure with a size of about $3 \mu \mathrm{m}$, and the microspheres are composed of numerous nanorods. The superior micro-/nanostructured morphology of the composite is achieved when compared to that of the pristine $\mathrm{NiCo}_{2} \mathrm{~S}_{4}$ where only the microspheres with irregular and larger sizes are obtained as exhibited in Fig.
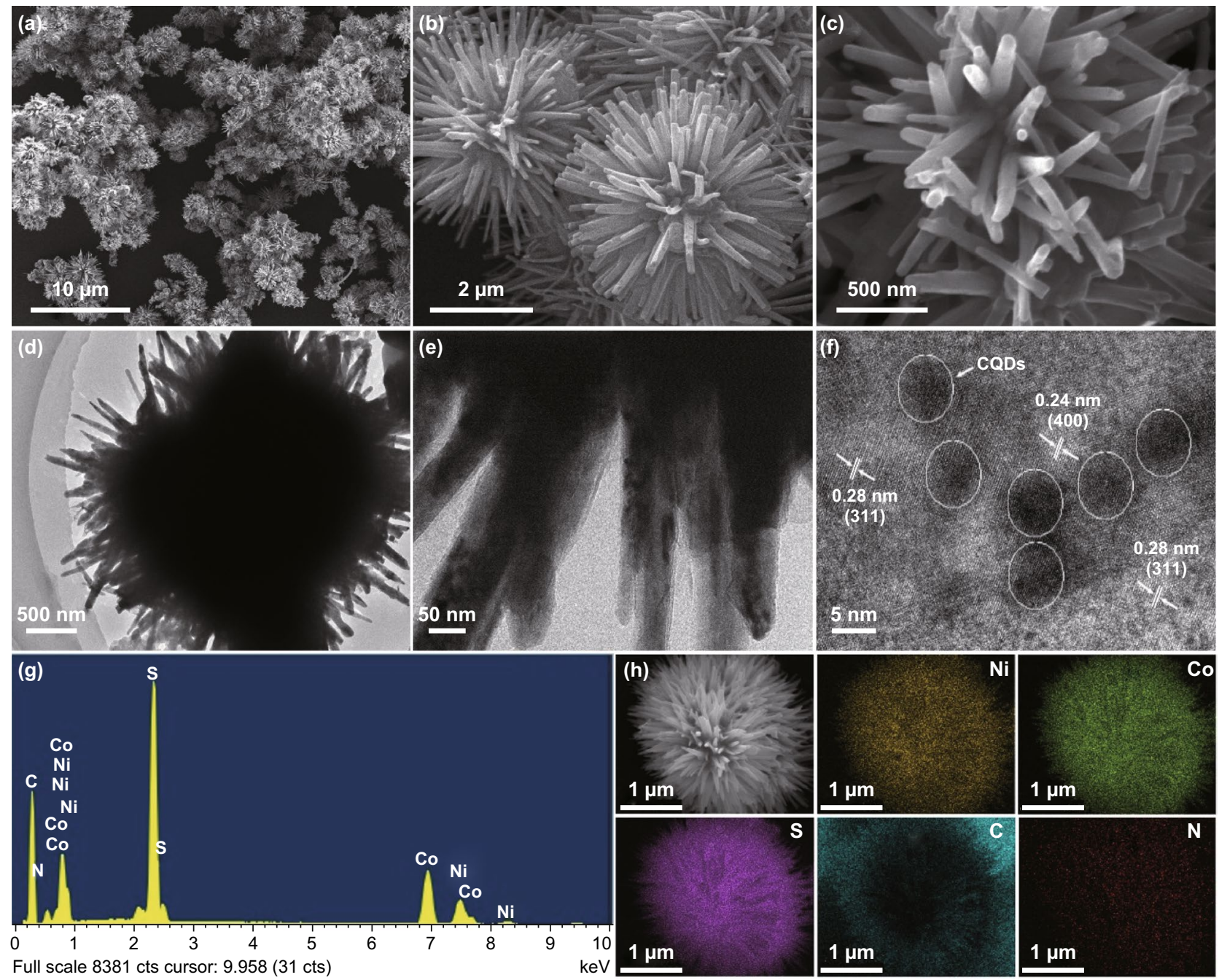

Fig. 3 a-c FESEM images, d, e TEM images, $\mathbf{f}$ HRTEM image, $\mathbf{g}$ EDS spectrum and $\mathbf{h}$ corresponding elemental mappings of Ni, Co, S, C and $\mathrm{N}$ elements of the $\mathrm{N}, \mathrm{S}-\mathrm{CQDS} / \mathrm{NiCo}_{2} \mathrm{~S}_{4}$ composite 
$\mathrm{S} 3$, which is ascribed to the induced role of CQDs during the formation process of the composite. The micro-/nanostructured morphology of the composite was further surveyed by TEM and HRTEM. The TEM images (Fig. 3d, e) reveal the nanorods-assembled urchin-like microsphere structure with a size of approximately $3 \mu \mathrm{m}$, which is well matched with the FESEM images. As displayed in Fig. 3f, the HRTEM image of the composite shows that the CQDs are well combined with $\mathrm{NiCo}_{2} \mathrm{~S}_{4}$ to obtain the uniform composite structure. Moreover, the HRTEM image exhibits the lattice fringes of 0.28 and $0.24 \mathrm{~nm}$, which, respectively, accord well with the (311) and (400) planes of $\mathrm{NiCo}_{2} \mathrm{~S}_{4}$. In addition, the EDS analysis (Fig. 3g) and corresponding elemental mappings
(Fig. 3h) show the existence of Ni, Co, S, C and N, suggesting the formation of $\mathrm{N}, \mathrm{S}-\mathrm{CQDS} / \mathrm{NiCo}_{2} \mathrm{~S}_{4}$ composite.

$\mathrm{XRD}$ was employed to examine the phase and structure of the pristine $\mathrm{NiCo}_{2} \mathrm{~S}_{4}$ and N,S-CQDs/NiCo $\mathrm{S}_{4}$ composite, and the results are exhibited in Fig. 4a. The main diffraction peaks of the pristine $\mathrm{NiCo}_{2} \mathrm{~S}_{4}$ and N,S-CQDs/ $\mathrm{NiCO}_{2} \mathrm{~S}_{4}$ composite can be clearly observed from the XRD patterns, which all well correspond to the $\mathrm{NiCo}_{2} \mathrm{~S}_{4}$ (JCPDS Card No. 20-0782), suggesting that the structure of the composite is not changed in the combination of N,S-CQDs and $\mathrm{NiCo}_{2} \mathrm{~S}_{4}$. However, it is hard to notice the peak of N,S-CQDs due to the relatively low content and weak diffraction peak intensity. Raman spectra were used to further characterize the structure of the pristine $\mathrm{NiCO}_{2} \mathrm{~S}_{4}$ and N,S-CQDs/
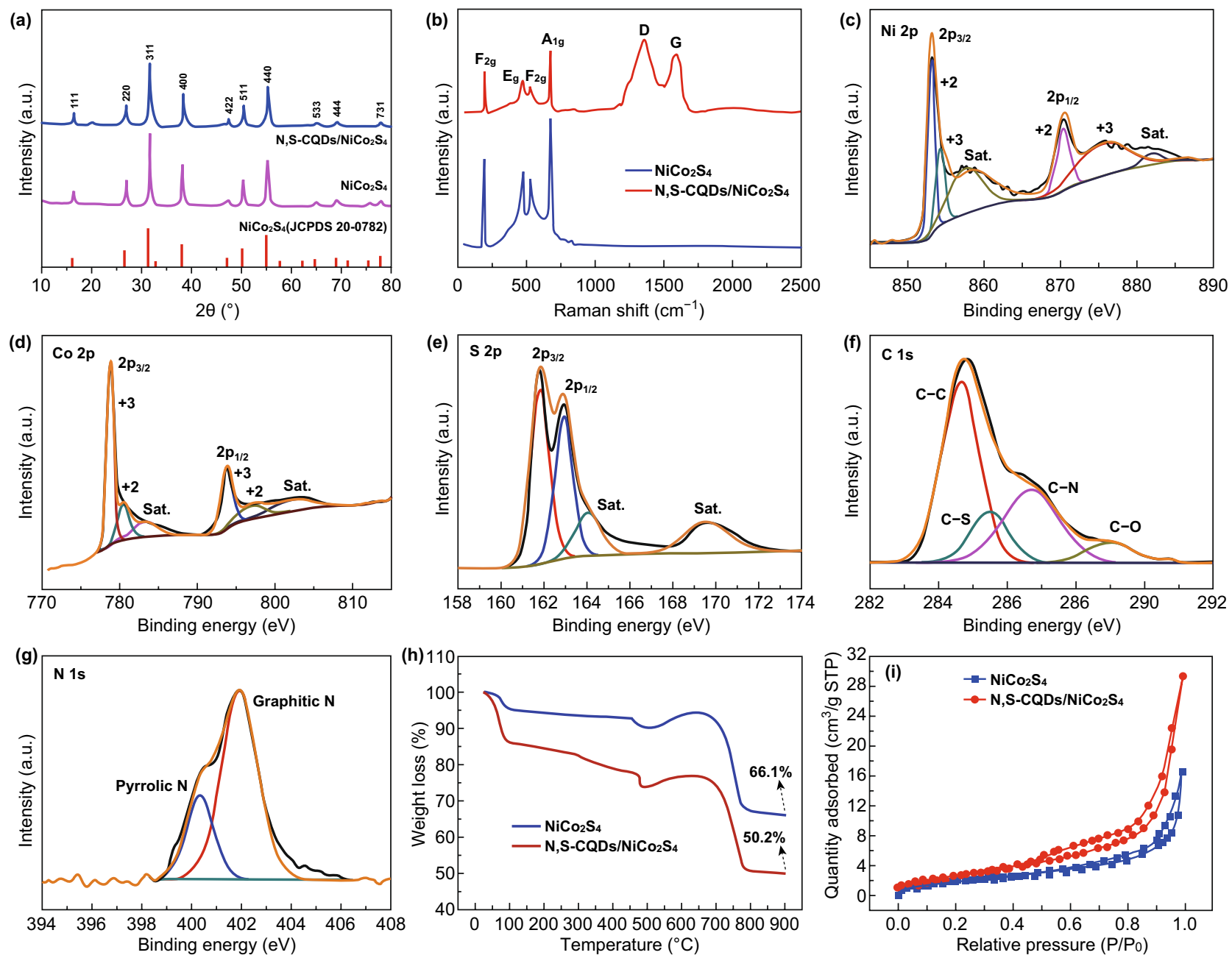

Fig. 4 a XRD patterns, b Raman spectra of the pristine $\mathrm{NiCo}_{2} \mathrm{~S}_{4}$ and $\mathrm{N}, \mathrm{S}-\mathrm{CQD} / \mathrm{NiCo}_{2} \mathrm{~S}_{4}$ composite. XPS high-resolution spectra of $\mathbf{c}$ Ni $2 \mathrm{p}$, $\mathbf{d}$ Co 2 p, e S 2p, f C 1s and $\mathbf{g ~ N} 1 \mathrm{~s}$ of the N,S-CQDs/ $/ \mathrm{NiCo}_{2} \mathrm{~S}_{4}$ composite. $\mathbf{h}$ TG curves and $\mathbf{i}$ Nitrogen adsorption-desorption isotherms of the N,SCQDs/ $/ \mathrm{NiCo}_{2} \mathrm{~S}_{4}$ composite 
$\mathrm{NiCo}_{2} \mathrm{~S}_{4}$ composite (Fig. 4b). Four peaks all can be seen for the pristine $\mathrm{NiCo}_{2} \mathrm{~S}_{4}$ and $\mathrm{N}, \mathrm{S}-\mathrm{CQD} / \mathrm{NiCo}_{2} \mathrm{~S}_{4}$ composite, which correspond to two $F_{2 g}\left(191\right.$ and $\left.524 \mathrm{~cm}^{-1}\right)$, one $E_{g}\left(472 \mathrm{~cm}^{-1}\right)$ and one $A_{1 g}\left(675 \mathrm{~cm}^{-1}\right)$ Raman modes of $\mathrm{NiCo}_{2} \mathrm{~S}_{4}$ [29]. Moreover, the D-band (disordered carbon) and G-band (ordered graphitic carbon) situated at 1356 and $1590 \mathrm{~cm}^{-1}$ are characteristic Raman modes of carbon, which are seen from the Raman spectroscopy of the N,S-CQDs/ $\mathrm{NiCo}_{2} \mathrm{~S}_{4}$ composite.

XPS was further undertaken to study the elemental composition and valence state of the as-synthesized N,S-CQDs/ $\mathrm{NiCo}_{2} \mathrm{~S}_{4}$ composite, as presented in Fig. $4 \mathrm{c}-\mathrm{g}$. The survey spectrum (Fig. S4) demonstrates the coexistence of Ni, Co, $\mathrm{S}, \mathrm{C}, \mathrm{O}$ and N. Figure $4 \mathrm{c}, \mathrm{d}$, respectively, exhibits the spectra of Ni $2 p$ and Co 2p. The two peaks situated at 853.04 and $870.44 \mathrm{eV}$ are indexed to $\mathrm{Ni}^{2+}$, and another two peaks situated at 854.24 and $876.04 \mathrm{eV}$ are indexed to $\mathrm{Ni}^{3+}$, respectively [41]. Similarly, the two peaks situated at 780.54 and $797.24 \mathrm{eV}$ can be ascribed to $\mathrm{Co}^{2+}$, and another two peaks situated at 778.74 and $793.79 \mathrm{eV}$ can be attributed to $\mathrm{Co}^{3+}$, respectively [41]. The S 2p spectrum presented in Fig. 4e represents two main peaks situated at 161.9 and $163.0 \mathrm{eV}$, which are, respectively, ascribed to the $\mathrm{S}^{2-}$ in low coordination at the surface and the metal-sulfur bonds [34]. For the C $1 \mathrm{~s}$ spectrum (Fig. 4f), four main peaks situated at 284.64 , $285.49,286.70$ and $289.04 \mathrm{eV}$ are, respectively, assigned to the $\mathrm{C}-\mathrm{C}, \mathrm{C}-\mathrm{S}, \mathrm{C}-\mathrm{N}$ and $\mathrm{C}-\mathrm{O}$ bonds [24], and the as-formed $\mathrm{C}-\mathrm{S}$ and $\mathrm{C}-\mathrm{N}$ bonds indicate that the nitrogen and sulfur elements are successfully codoped into CQDs. Furthermore, Fig. 4g displays the $\mathrm{N} 1 \mathrm{~s}$ spectrum with two main peaks situated at 400.3 and $401.9 \mathrm{eV}$, which correspond to the pyrrolic $\mathrm{N}$ and graphitic $\mathrm{N}$ [42]. Based on these results above, the XPS characterization exhibits the coexistence of $\mathrm{Ni}, \mathrm{Co}$, $\mathrm{S}, \mathrm{C}$ and $\mathrm{N}$ elements in the $\mathrm{N}, \mathrm{S}-\mathrm{CQDs} / \mathrm{NiCo}_{2} \mathrm{~S}_{4}$ composite.

To further determine the composition of the prepared $\mathrm{N}, \mathrm{S}-\mathrm{CQD} / \mathrm{NiCo}_{2} \mathrm{~S}_{4}$ composite, the thermogravimetric analysis (TGA) was executed in air atmosphere from ambient temperature to $900{ }^{\circ} \mathrm{C}$ as demonstrated in Fig. 4h. The TG curves of the pristine $\mathrm{NiCo}_{2} \mathrm{~S}_{4}$ and $\mathrm{N}, \mathrm{S}-\mathrm{CQDs} / \mathrm{NiCo}_{2} \mathrm{~S}_{4}$ composite both show two apparent weight losses and one obvious weight gain. For the $\mathrm{N}, \mathrm{S}-\mathrm{CQDs} / \mathrm{NiCo}_{2} \mathrm{~S}_{4}$ composite, the first weight loss before $500{ }^{\circ} \mathrm{C}$ is more obvious than that of the pristine $\mathrm{NiCo}_{2} \mathrm{~S}_{4}$, which results from the burning of CQDs and the loss of physically adsorbed and crystalline water. The second apparent weight gain between 500 and $650{ }^{\circ} \mathrm{C}$ is attributed to the oxidation of $\mathrm{NiCo}_{2} \mathrm{~S}_{4}$ to $\mathrm{NiSO}_{4}$ and $\mathrm{CoSO}_{4}$, and the third evident weight loss in the temperature range of 650 and $800{ }^{\circ} \mathrm{C}$ is ascribed to the further burning of CQDs as well as the decomposition of $\mathrm{NiSO}_{4}$ and $\mathrm{CoSO}_{4}$ to stable $\mathrm{NiO}$ and $\mathrm{CoO}$ as reported in the literature [43-45]. From the different weight losses of the pristine $\mathrm{NiCo}_{2} \mathrm{~S}_{4}$ and $\mathrm{N}, \mathrm{S}-\mathrm{CQDs} / \mathrm{NiCo}_{2} \mathrm{~S}_{4}$ composite, it is deduced that the content of CQDs in composite is about $15.9 \mathrm{wt} \%$. $\mathrm{N}_{2}$ adsorption/desorption test was employed to research the specific surface area of the pristine $\mathrm{NiCo}_{2} \mathrm{~S}_{4}$ and N,S-CQDs/ $\mathrm{NiCo}_{2} \mathrm{~S}_{4}$ composite, as presented in Fig. 4i. The N,S-CQDs/ $\mathrm{NiCo}_{2} \mathrm{~S}_{4}$ composite manifests a greater specific surface area $\left(27.2 \mathrm{~m}^{2} \mathrm{~g}^{-1}\right)$ than that of the pristine $\mathrm{NiCo}_{2} \mathrm{~S}_{4}\left(14.9 \mathrm{~m}^{2} \mathrm{~g}^{-1}\right)$, which contributes to the enhancement of electrochemical properties.

The electrochemical performances of the $\mathrm{NiCo}_{2} \mathrm{~S}_{4}$ and $\mathrm{N}, \mathrm{S}-\mathrm{CQDs} / \mathrm{NiCo}_{2} \mathrm{~S}_{4}$ electrodes were investigated in a threeelectrode configuration with $2 \mathrm{M} \mathrm{KOH}$ solution as electrolyte. Figure 5a shows the comparison of the $\mathrm{CV}$ curves of $\mathrm{NiCo}_{2} \mathrm{~S}_{4}$ and $\mathrm{N}, \mathrm{S}-\mathrm{CQDs} / \mathrm{NiCo}_{2} \mathrm{~S}_{4}$ electrodes at $20 \mathrm{mV} \mathrm{s}^{-1}$ in the potential range of 0 to $0.6 \mathrm{~V}$. The two electrodes both manifest strong and broad redox peaks in the $\mathrm{CV}$ curves, implying the combination of Faradaic battery and doublelayer capacitive behavior. The Faradaic battery behavior is derived from reversible redox reactions of $\mathrm{Ni}^{2+} / \mathrm{Ni}^{3+}$ and $\mathrm{Co}^{2+} / \mathrm{Co}^{3+} / \mathrm{Co}^{4+}$ according to Eqs. 1-3 [34]:

$\mathrm{NiS}+\mathrm{OH}^{-} \leftrightarrow \mathrm{NiSOH}+\mathrm{e}^{-}$

$\mathrm{CoS}+\mathrm{OH}^{-} \leftrightarrow \mathrm{CoSOH}+\mathrm{e}^{-}$

$\mathrm{CoSOH}+\mathrm{OH}^{-} \leftrightarrow \mathrm{CoSO}+\mathrm{H}_{2} \mathrm{O}+\mathrm{e}^{-}$

Ex situ XRD measurement was utilized to characterize the phase change of the N,S-CQDs/ $\mathrm{NiCo}_{2} \mathrm{~S}_{4}$ composite during different electrochemical steps, as exhibited in Fig. 5d. The alteration in reflections indicates the phase change in the charge-discharge process and verifies that Faradaic redox reactions occur in bulk, demonstrating the feature of Faradaic battery. Furthermore, it is clear that the area of $\mathrm{CV}$ curve of the $\mathrm{N}, \mathrm{S}-\mathrm{CQD} / \mathrm{NiCo}_{2} \mathrm{~S}_{4}$ electrode is greater than that of the $\mathrm{NiCo}_{2} \mathrm{~S}_{4}$ electrode, revealing that the N,S-CQDs/ $\mathrm{NiCo}_{2} \mathrm{~S}_{4}$ electrode shows higher specific capacity. Figure 5b, c displays the $\mathrm{CV}$ curves of the $\mathrm{NiCo}_{2} \mathrm{~S}_{4}$ and N,S-CQDs/ $\mathrm{NiCo}_{2} \mathrm{~S}_{4}$ electrodes at different scan rates, respectively. The $\mathrm{N}, \mathrm{S}-\mathrm{CQDs} / \mathrm{NiCo}_{2} \mathrm{~S}_{4}$ electrode manifests a smaller peak position shift than that of the $\mathrm{NiCo}_{2} \mathrm{~S}_{4}$ electrode as the scanning speed increases from 5 to $100 \mathrm{mV} \mathrm{s}^{-1}$, suggesting 

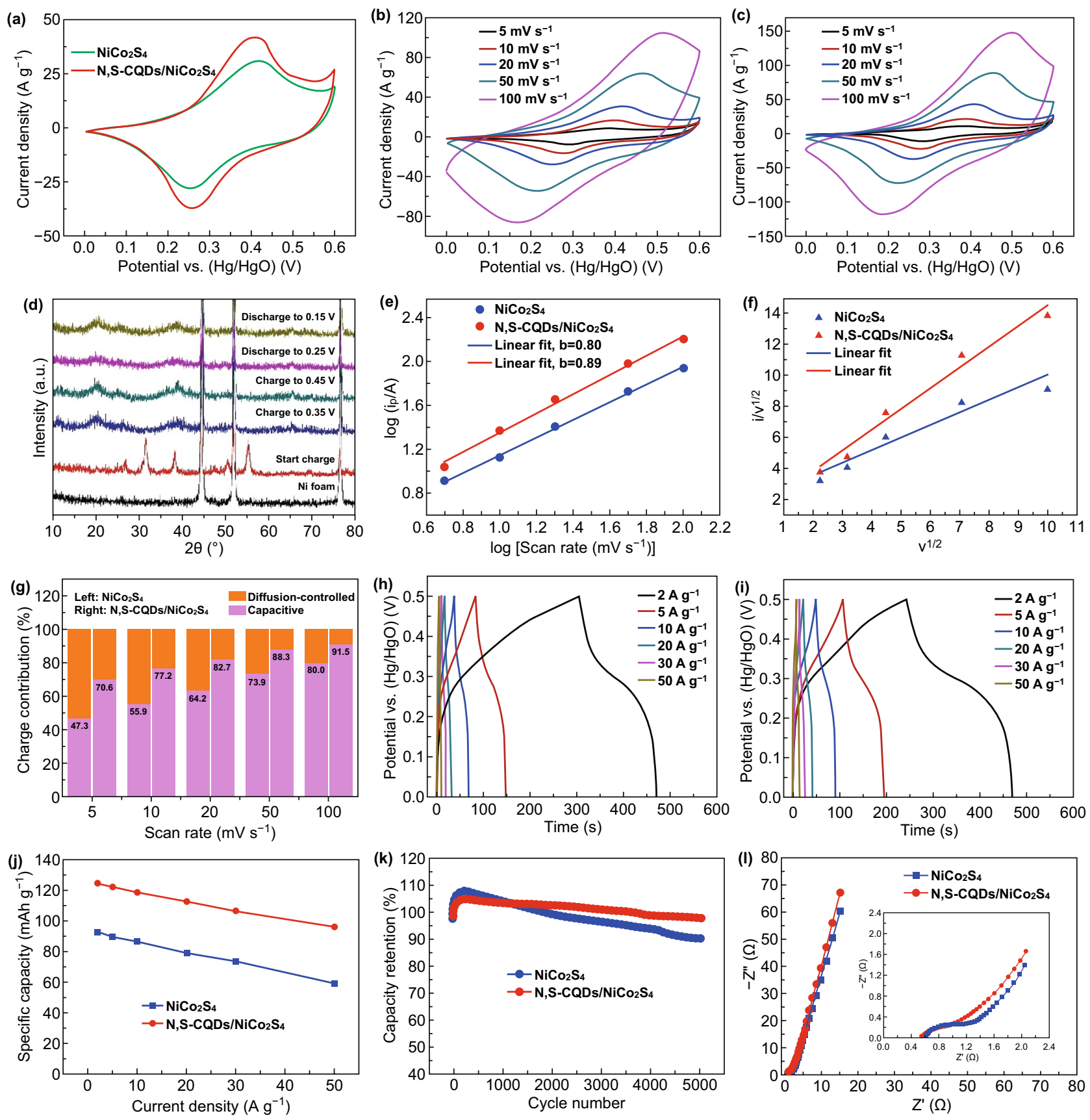

Fig. 5 a Comparison of $\mathrm{CV}$ curves of the pristine $\mathrm{NiCo}_{2} \mathrm{~S}_{4}$ and $\mathrm{N}, \mathrm{S}-\mathrm{CQDs} / \mathrm{NiCo}_{2} \mathrm{~S}_{4}$ electrodes at $20 \mathrm{mV} \mathrm{s}^{-1}$. CV curves at various scan rates of the $\mathbf{b}$ pristine $\mathrm{NiCo}_{2} \mathrm{~S}_{4}$ and $\mathbf{c} \mathrm{N}, \mathrm{S}-\mathrm{CQD} / \mathrm{NiCo}_{2} \mathrm{~S}_{4}$ electrodes. $\mathbf{d}$ Ex-situ XRD measurement of the N,S-CQDs/NiCo $\mathrm{S}_{4}$ electrode during different electrochemical steps. $\mathbf{e}$ The fitting lines of $\log \left(\mathrm{scan}\right.$ rate, $\left.\mathrm{mV} \mathrm{s}^{-1}\right)-\log \left(\mathrm{i}_{\mathrm{p}}, \mathrm{A}\right), \mathbf{f} \mathrm{i} / \nu^{1 / 2}-\nu^{1 / 2}$, and $\mathbf{g}$ the charge contribution of the pristine $\mathrm{NiCo}_{2} \mathrm{~S}_{4}$ and $\mathrm{N}, \mathrm{S}-\mathrm{CQD} / \mathrm{NiCo}_{2} \mathrm{~S}_{4}$ electrodes. GCD curves at various current densities of the $\mathbf{h}$ pristine $\mathrm{NiCo}_{2} \mathrm{~S}_{4}$ and $\mathbf{i} \mathrm{N}, \mathrm{S}-\mathrm{CQDs} / \mathrm{NiCo}_{2} \mathrm{~S}_{4}$ electrodes. $\mathbf{j}$ The rate performances, $\mathbf{k}$ cycling performances, and $\mathbf{I}$ EIS plots of the pristine $\mathrm{NiCo}_{2} \mathrm{~S}_{4}$ and $\mathrm{N}, \mathrm{S}-\mathrm{CQDs} / \mathrm{NiCo}_{2} \mathrm{~S}_{4}$ electrodes

that the composite electrode has lower polarization, better conductivity and faster electrochemical kinetic. To further explore the difference of the electrochemical behaviors of the $\mathrm{NiCo}_{2} \mathrm{~S}_{4}$ and $\mathrm{N}, \mathrm{S}-\mathrm{CQDs} / \mathrm{NiCo}_{2} \mathrm{~S}_{4}$ electrodes, the quantitative analysis was conducted based on the mechanism of charge storage. The relationship of the peak currents $\left(i_{\mathrm{p}}\right)$ and scan rates is expressed as $I=a v^{b}$ shown in Fig. 5e [26], where the $b$-value of 0.5 and 1 suggests the 
diffusion-controlled and surface capacitive processes of the electrochemical reaction, respectively. The calculated $b$-value of the $\mathrm{NiCo}_{2} \mathrm{~S}_{4}$ and $\mathrm{N}, \mathrm{S}-\mathrm{CQDS} / \mathrm{NiCo}_{2} \mathrm{~S}_{4}$ electrodes is, respectively, 0.80 and 0.89 , indicating a mixed behavior of diffusion-controlled and surface capacitive processes. The higher $b$-value of the $\mathrm{N}, \mathrm{S}-\mathrm{CQD} / \mathrm{NiCo}_{2} \mathrm{~S}_{4}$ electrode signifies more surface capacitive behaviors. Furthermore, the result is further verified by the quantitative calculation of the contribution of the diffusion-controlled and surface capacitive charge, which is obtained from the following equation [26]: $i(V)=k_{1} v+k_{2} v^{1 / 2}$, in which $k_{1} v$ represents the surface capacitive current and $k_{2} v^{1 / 2}$ denotes the diffusion-controlled current. The fitted lines of the $i / v^{1 / 2}$ to $v^{1 / 2}$ of the two electrodes are presented in Fig. 5f, and the values of the slope and intercepts, respectively, represent the constants of $k_{l}$ and $k_{2}$. The charge contributions of the $\mathrm{NiCo}_{2} \mathrm{~S}_{4}$ and $\mathrm{N}, \mathrm{S}-\mathrm{CQDs} / \mathrm{NiCo}_{2} \mathrm{~S}_{4}$ electrodes are manifested in Fig. $5 \mathrm{~g}$, and it is visible that the $\mathrm{N}, \mathrm{S}-\mathrm{CQDs} / \mathrm{NiCo}_{2} \mathrm{~S}_{4}$ electrode displays larger capacitive contribution ratio than that of the $\mathrm{NiCo}_{2} \mathrm{~S}_{4}$ electrode at all scan rates, which reasonably elucidates why the N,S-CQDs/ $\mathrm{NiCo}_{2} \mathrm{~S}_{4}$ electrode possesses faster electrochemical kinetic than that of the $\mathrm{NiCo}_{2} \mathrm{~S}_{4}$ electrode.

Figure 5h, i exhibits the GCD curves of the $\mathrm{NiCo}_{2} \mathrm{~S}_{4}$ and $\mathrm{N}, \mathrm{S}-\mathrm{CQDs} / \mathrm{NiCo}_{2} \mathrm{~S}_{4}$ electrodes at different current densities in the potential window of $0-0.5 \mathrm{~V}$, respectively. The GCD curves of the N,S-CQDs/ $/ \mathrm{NiCO}_{2} \mathrm{~S}_{4}$ electrode present a better symmetry than that of the pristine $\mathrm{NiCo}_{2} \mathrm{~S}_{4}$ electrode, signifying that the composite electrode has lower resistance and higher rate performance. The specific capacities of the two electrodes are calculated according to the GCD curves, as exhibited in Fig. 5j. The specific capacity of the N,S-CQDs/ $\mathrm{NiCo}_{2} \mathrm{~S}_{4}$ electrode is, respectively, 124.4, 122.4, 118.6, 112.8, 106.4 and 96.1 $\mathrm{mAh} \mathrm{g}^{-1}$ at 2, 5, 10, 20, 30 and $50 \mathrm{~A}$ $\mathrm{g}^{-1}$, which is better than that of the $\mathrm{NiCo}_{2} \mathrm{~S}_{4}$ electrode (from $92.8 \mathrm{mAh} \mathrm{g}^{-1}$ at $2 \mathrm{~A} \mathrm{~g}^{-1}$ to $59.1 \mathrm{mAh} \mathrm{g}^{-1}$ at $50 \mathrm{~A} \mathrm{~g}^{-1}$ ). Correspondingly, the $\mathrm{N}, \mathrm{S}-\mathrm{CQD} / \mathrm{NiCo}_{2} \mathrm{~S}_{4}$ electrode manifests a greater capacity retention of $77.3 \%$ at $50 \mathrm{~A} \mathrm{~g}^{-1}$ than that of the $\mathrm{NiCo}_{2} \mathrm{~S}_{4}$ electrode $(63.7 \%$ of capacity retention at $50 \mathrm{~A}$ $\left.\mathrm{g}^{-1}\right)$. The improved specific capacity and rate performance of the $\mathrm{N}, \mathrm{S}-\mathrm{CQDs} / \mathrm{NiCo}_{2} \mathrm{~S}_{4}$ electrode originate from the positive synergistic effect between highly conductive N,S-CQDs with the capacitive feature and high-capacity $\mathrm{NiCo}_{2} \mathrm{~S}_{4}$ with Faradaic characteristic. Note that the specific capacity and rate performance of the as-obtained $\mathrm{N}, \mathrm{S}-\mathrm{CQDs} / \mathrm{NiCo}_{2} \mathrm{~S}_{4}$ composite are comparable or even higher than those of nickel cobalt sulfide-based composite as reported in the literature [46-53]. The cycling property of the $\mathrm{NiCo}_{2} \mathrm{~S}_{4}$ and $\mathrm{N}, \mathrm{S}-\mathrm{CQD} / \mathrm{NiCo}_{2} \mathrm{~S}_{4}$ electrodes was surveyed by the repeated GCD tests at $5 \mathrm{~A} \mathrm{~g} \mathrm{~g}^{-1}$ in the potential range of $0-0.5 \mathrm{~V}$ over 5000 cycles, as exhibited in Fig. 5k. The specific capacity of the two electrodes increases in the first hundreds of cycles due to the gradually sufficient activation process and then reduces with a gradual decline as the increasing cycles $[23,26]$. After 5000 cycles, the N,S-CQDs $/ \mathrm{NiCo}_{2} \mathrm{~S}_{4}$ electrode manifests a better cycle property with $97.9 \%$ of the initial capacity retention than that of the $\mathrm{NiCo}_{2} \mathrm{~S}_{4}$ electrode (90.3\%), revealing the excellent cycling stability of the asresulted composite electrode. Additionally, the EIS test was utilized to illustrate the superior electrochemical behaviors, which was implemented in the frequency range of $0.01 \mathrm{~Hz}$ to $100 \mathrm{kHz}$ at the open-circuit potential (Fig. 51). The Nyquist plot consists of the intercept and depressed semicircle in the high-frequency region as well as the slope line in the lowfrequency region $[54,55]$. The $\mathrm{N}, \mathrm{S}-\mathrm{CQDS} / \mathrm{NiCo}_{2} \mathrm{~S}_{4}$ electrode displays smaller intercept, lower semicircle diameter and higher slope value than those of the $\mathrm{NiCo}_{2} \mathrm{~S}_{4}$ electrode, indicating the lower resistance and better electrical conductivity of the composite electrode, leading to the improved electrochemical properties.

\subsection{Physicochemical and Electrochemical Characterizations of the Anode Materials}

Figures $6 \mathrm{a}$ and S5 display the FESEM images of the $\mathrm{N}-\mathrm{rGO} / \mathrm{Fe}_{2} \mathrm{O}_{3}$ composite, and it is clearly observed that the prism-like $\mathrm{Fe}_{2} \mathrm{O}_{3}$ hexahedrons are tightly wrapped by the N-rGO layers, suggesting the close contact between the $\mathrm{Fe}_{2} \mathrm{O}_{3}$ hexahedrons and the N-rGO sheets. Such a composite structure can increase their contact and hinder the agglomeration of $\mathrm{Fe}_{2} \mathrm{O}_{3}$ and $\mathrm{N}$-rGO, thereby promoting the improvement of electrochemical activity and stability of the composite. TEM study demonstrated in Figs. $6 \mathrm{~b}$ and S6 was employed to verify the formation of the N-rGO/ $\mathrm{Fe}_{2} \mathrm{O}_{3}$ composite, and the prism-like $\mathrm{Fe}_{2} \mathrm{O}_{3}$ hexahedrons with a size of about $100 \mathrm{~nm}$ were well combined with $\mathrm{N}$-doped rGO sheets to form the composite. It is noted that the pristine $\mathrm{Fe}_{2} \mathrm{O}_{3}$ displays the morphology of prism-like hexahedrons from the FESEM and TEM images demonstrated in Figs. S7 and S8, indicating that the morphology of the composite is not altered in the combination of $\mathrm{Fe}_{2} \mathrm{O}_{3}$ and N-rGO. As exhibited in Fig. 6c, the HRTEM 

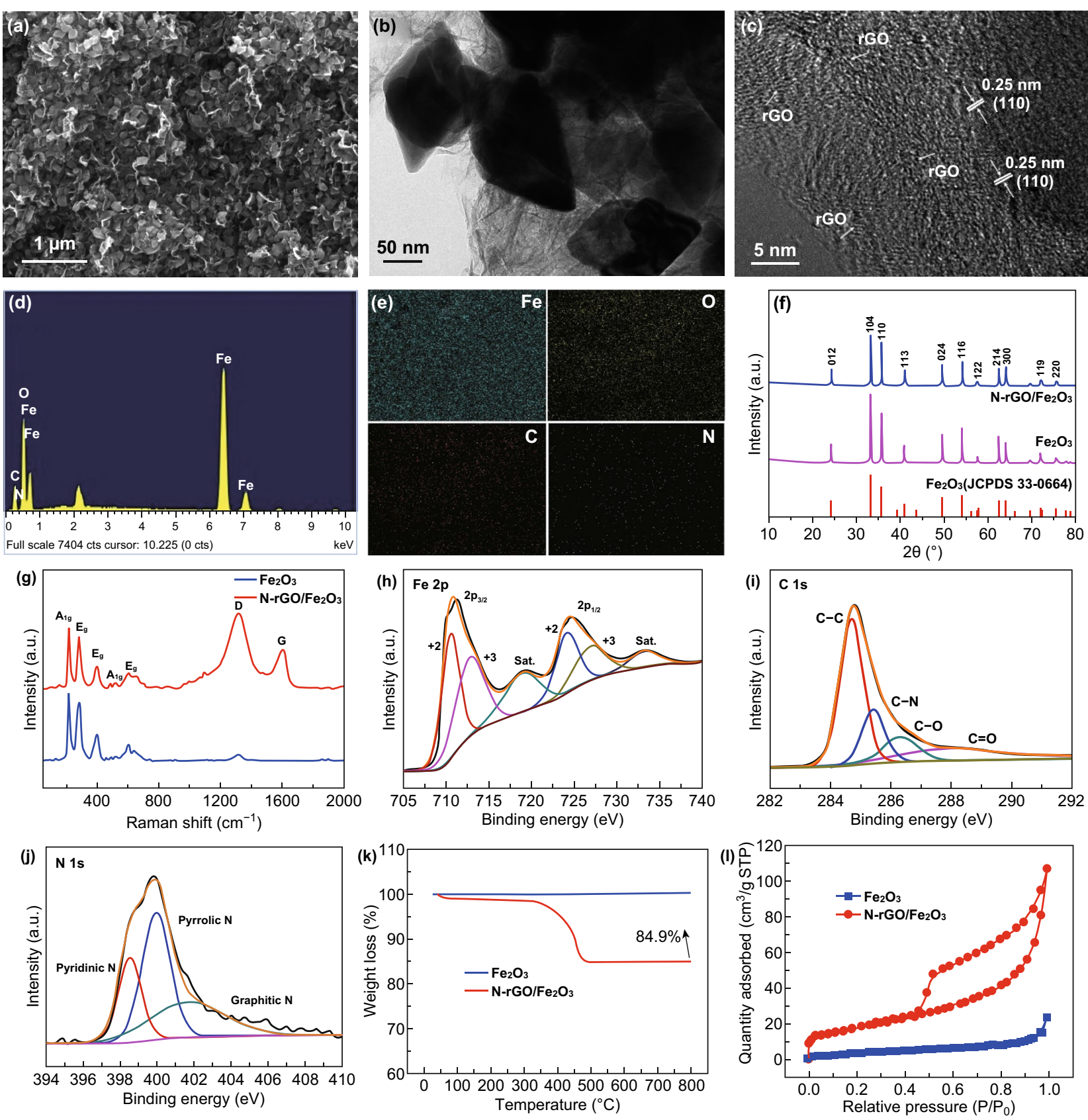

Fig. 6 a FESEM image, b TEM image, c HRTEM image, d EDS spectrum and e corresponding elemental mappings of Fe, O, C and N elements of the $\mathrm{N}-\mathrm{rGO} / \mathrm{Fe}_{2} \mathrm{O}_{3}$ composite. $\mathbf{f}$ XRD patterns and $\mathbf{g}$ Raman spectra of the pristine $\mathrm{Fe}_{2} \mathrm{O}_{3}$ and $\mathrm{N}-\mathrm{rGO} / \mathrm{Fe}_{2} \mathrm{O}_{3}$ composite. XPS high-resolution spectra of $\mathbf{h}$ Fe 2 p, i C $1 \mathrm{~s}$ and $\mathbf{j} \mathrm{N}$ 1s of the $\mathrm{N}-\mathrm{rGO} / \mathrm{Fe}_{2} \mathrm{O}_{3}$ composite. $\mathbf{k}$ TG curves and $\mathbf{l}$ nitrogen adsorption-desorption isotherms of the $\mathrm{N}-\mathrm{rGO} / \mathrm{Fe}_{2} \mathrm{O}_{3}$ composite

image indicates the presence of crumpled $\mathrm{N}-\mathrm{rGO}$, and the lattice fringe of $0.25 \mathrm{~nm}$ matches well with the (110) crystal plane of $\mathrm{Fe}_{2} \mathrm{O}_{3}$. EDS and the corresponding elemental mappings were utilized to examine the elemental composition and distribution of the $\mathrm{N}-\mathrm{rGO} / \mathrm{Fe}_{2} \mathrm{O}_{3}$ composite.
The EDS spectrum (Fig. 6d) verifies the existence of Fe, $\mathrm{O}, \mathrm{C}$, and $\mathrm{N}$ in the composite, and elemental mappings (Fig. 6e) reveal that these elements are uniformly distributed throughout the composite. 
XRD was utilized to further characterize the structure and phase of the pristine $\mathrm{Fe}_{2} \mathrm{O}_{3}$ and $\mathrm{N}-\mathrm{rGO} / \mathrm{Fe}_{2} \mathrm{O}_{3}$ composite (Fig. 6f). The XRD patterns show the strong diffraction peaks of the pristine $\mathrm{Fe}_{2} \mathrm{O}_{3}$ and $\mathrm{N}-\mathrm{rGO} / \mathrm{Fe}_{2} \mathrm{O}_{3}$ composite, which are both well fitted to the $\mathrm{Fe}_{2} \mathrm{O}_{3}$ (JCPDS Card No. 33-0664). Note that the characteristic peaks of rGO cannot be observed in the XRD pattern of the composite, which results from the weak and broad peak and low rGO content in composite. Raman spectra were used to further examine the structure of the pristine $\mathrm{Fe}_{2} \mathrm{O}_{3}$ and N-rGO/Fe ${ }_{2} \mathrm{O}_{3}$ composite (Fig. 6g). Five peaks all can be seen from the Raman spectra of the pristine $\mathrm{Fe}_{2} \mathrm{O}_{3}$ and $\mathrm{N}-\mathrm{rGO} / \mathrm{Fe}_{2} \mathrm{O}_{3}$ composite, which are attributed to two $A_{1 g}\left(218\right.$ and $\left.483 \mathrm{~cm}^{-1}\right)$ and three $E_{g}\left(283,399\right.$, and $\left.601 \mathrm{~cm}^{-1}\right)$ Raman modes of $\mathrm{Fe}_{2} \mathrm{O}_{3}$ [56]. Besides, two typical peaks situated at 1320 and $1596 \mathrm{~cm}^{-1}$ are assigned to the D-band and G-band, respectively, further suggesting that the $\mathrm{Fe}_{2} \mathrm{O}_{3}$ is successfully combined with the $\mathrm{N}-\mathrm{rGO}$ to form the composite.

XPS was further applied to explore the elemental composition and valence state of the obtained $\mathrm{N}-\mathrm{rGO} / \mathrm{Fe}_{2} \mathrm{O}_{3}$ composite, as presented in Fig. $6 \mathrm{~h}-\mathrm{j}$. The survey spectrum (Fig. S9) demonstrates the existence of Fe, O, C and $\mathrm{N}$ in the $\mathrm{N}-\mathrm{rGO} / \mathrm{Fe}_{2} \mathrm{O}_{3}$ composite. For the Fe $2 \mathrm{p}$ spectrum (Fig. 6h), the peaks situated at 710.5 and $724.1 \mathrm{eV}$ are assigned to $\mathrm{Fe}^{2+}$, and the peaks situated at 712.8 and $726.8 \mathrm{eV}$ are well fitted to $\mathrm{Fe}^{3+}$ [57]. As for the $\mathrm{C} 1 \mathrm{~s}$ spectrum shown in Fig. 6i, the peaks located at 284.7, 285.4, 286.3 and $288.1 \mathrm{eV}$ correspond to the $\mathrm{C}-\mathrm{C}, \mathrm{C}-\mathrm{N}, \mathrm{C}-\mathrm{O}$ and $\mathrm{C}=\mathrm{O}$ bonds [58], and the as-formed $\mathrm{C}-\mathrm{N}$ bond implies that the nitrogen element is well doped into rGO. Furthermore, the $\mathrm{N} 1 \mathrm{~s}$ spectrum manifested in Fig. 6j reveals that the peaks located at 398.5, 399.9 and $401.6 \mathrm{eV}$ correspond well with the pyridinic N, pyrrolic $\mathrm{N}$ and graphitic $\mathrm{N}$ [59]. Thus, the XPS analysis further proves the formation of the N-rGO/ $\mathrm{Fe}_{2} \mathrm{O}_{3}$ composite.

The content of GO in N-rGO/ $\mathrm{Fe}_{2} \mathrm{O}_{3}$ composite was determined by TGA test, which is executed in air atmosphere from room temperature to $800^{\circ} \mathrm{C}$ as demonstrated in Fig. 6k. From the TGA curves, almost no weight loss of the pristine $\mathrm{Fe}_{2} \mathrm{O}_{3}$ can be seen in the whole temperature range, suggesting the high stability of the $\mathrm{Fe}_{2} \mathrm{O}_{3}$ in air, while an obvious weight loss of the $\mathrm{N}-\mathrm{rGO} / \mathrm{Fe}_{2} \mathrm{O}_{3}$ composite can be observed between 350 and $470{ }^{\circ} \mathrm{C}$ due to the burning of rGO. Apparently, the $\mathrm{rGO}$ content in the $\mathrm{N}-\mathrm{rGO} / \mathrm{Fe}_{2} \mathrm{O}_{3}$ composite is deduced to be about $15.1 \mathrm{wt} \%$. As exhibited in Fig. 61, the BET specific surface areas of the pristine $\mathrm{Fe}_{2} \mathrm{O}_{3}$ and N-rGO/
$\mathrm{Fe}_{2} \mathrm{O}_{3}$ composite are obtained by the nitrogen adsorption/ desorption test. Benefiting from the introduction of $\mathrm{N}-\mathrm{rGO}$ in composite, the $\mathrm{N}-\mathrm{rGO} / \mathrm{Fe}_{2} \mathrm{O}_{3}$ composite displays a far greater BET specific surface area $\left(66.8 \mathrm{~m}^{2} \mathrm{~g}^{-1}\right)$ than that of the pristine $\mathrm{Fe}_{2} \mathrm{O}_{3}\left(13.8 \mathrm{~m}^{2} \mathrm{~g}^{-1}\right)$, and thus, it is expected that the $\mathrm{N}-\mathrm{rGO} / \mathrm{Fe}_{2} \mathrm{O}_{3}$ composite can present excellent electrochemical performances.

The electrochemical properties of the pristine $\mathrm{Fe}_{2} \mathrm{O}_{3}$ and $\mathrm{N}-\mathrm{rGO} / \mathrm{Fe}_{2} \mathrm{O}_{3}$ composite were also studied in a threeelectrode cell with $2 \mathrm{M} \mathrm{KOH}$ solution as electrolyte. Figure 7 a presents the comparison of $\mathrm{CV}$ curves of the $\mathrm{Fe}_{2} \mathrm{O}_{3}$ and $\mathrm{N}-\mathrm{rGO} / \mathrm{Fe}_{2} \mathrm{O}_{3}$ electrodes at $20 \mathrm{mV} \mathrm{s}^{-1}$ within the potential range of -1.2 to- $0.2 \mathrm{~V}$. Apparently, the composite electrode manifests a distinctly greater area of $\mathrm{CV}$ curve than that of the $\mathrm{Fe}_{2} \mathrm{O}_{3}$ electrode, implying that the composite electrode shows much larger specific capacity than that of the pristine $\mathrm{Fe}_{2} \mathrm{O}_{3}$ electrode. The substantially improved specific capacity of the composite electrode is ascribed to the positive synergistic effect of the doublelayer capacitive behavior of N-rGO and Faradaic redox reaction of $\mathrm{Fe}_{2} \mathrm{O}_{3}$. Ex situ XRD test (Fig. 7d) was also used to investigate the phase change of the $\mathrm{N}-\mathrm{rGO} / \mathrm{Fe}_{2} \mathrm{O}_{3}$ composite during different electrochemical steps. The observed change in reflections reveals the phase change in the charge/discharge process and confirms the occurring of Faradaic redox reactions, further demonstrating the typical battery characteristic. In comparison with the $\mathrm{Fe}_{2} \mathrm{O}_{3}$ electrode, the $\mathrm{N}-\mathrm{rGO} / \mathrm{Fe}_{2} \mathrm{O}_{3}$ electrode shows a smaller potential difference of the anodic and cathodic peak $\left(\Delta \mathrm{E}_{\mathrm{P}}\right)$, implying the lower resistance and better kinetic behavior. Figure 7b, c displays the CV curves of the $\mathrm{Fe}_{2} \mathrm{O}_{3}$ and $\mathrm{N}-\mathrm{rGO} / \mathrm{Fe}_{2} \mathrm{O}_{3}$ electrodes, respectively, and no distinct distortion can be noticed with the increasing scanning speed from 5 to $50 \mathrm{mV} \mathrm{s}^{-1}$. Figure 7e, f exhibits the GCD curves of the $\mathrm{Fe}_{2} \mathrm{O}_{3}$ and $\mathrm{N}-\mathrm{rGO} / \mathrm{Fe}_{2} \mathrm{O}_{3}$ electrodes at various current densities in the potential range between -1 and $-0.2 \mathrm{~V}$, respectively. The calculated specific capacity of the $\mathrm{N}-\mathrm{rGO} / \mathrm{Fe}_{2} \mathrm{O}_{3}$ electrode (Fig. $7 \mathrm{~g}$ ) is, respectively, 249.6, 228.4, 206.7, 174.2, 130.4 and $96.2 \mathrm{mAh} \mathrm{g}^{-1}$ at 1 , 2, 3, 5, 10 and $20 \mathrm{~A} \mathrm{~g}^{-1}$, which is much better than that of the $\mathrm{Fe}_{2} \mathrm{O}_{3}$ electrode (from 109.1 at $1 \mathrm{~A} \mathrm{~g}^{-1}$ to 21.8 $\mathrm{mAh} \mathrm{g}^{-1}$ at $20 \mathrm{~A} \mathrm{~g}^{-1}$ ). Moreover, the specific capacity of the $\mathrm{N}-\mathrm{rGO} / \mathrm{Fe}_{2} \mathrm{O}_{3}$ electrode is not only far higher than that of carbon-based anode materials, but also comparable to or even larger than that of most $\mathrm{Fe}_{2} \mathrm{O}_{3}$-based anode 

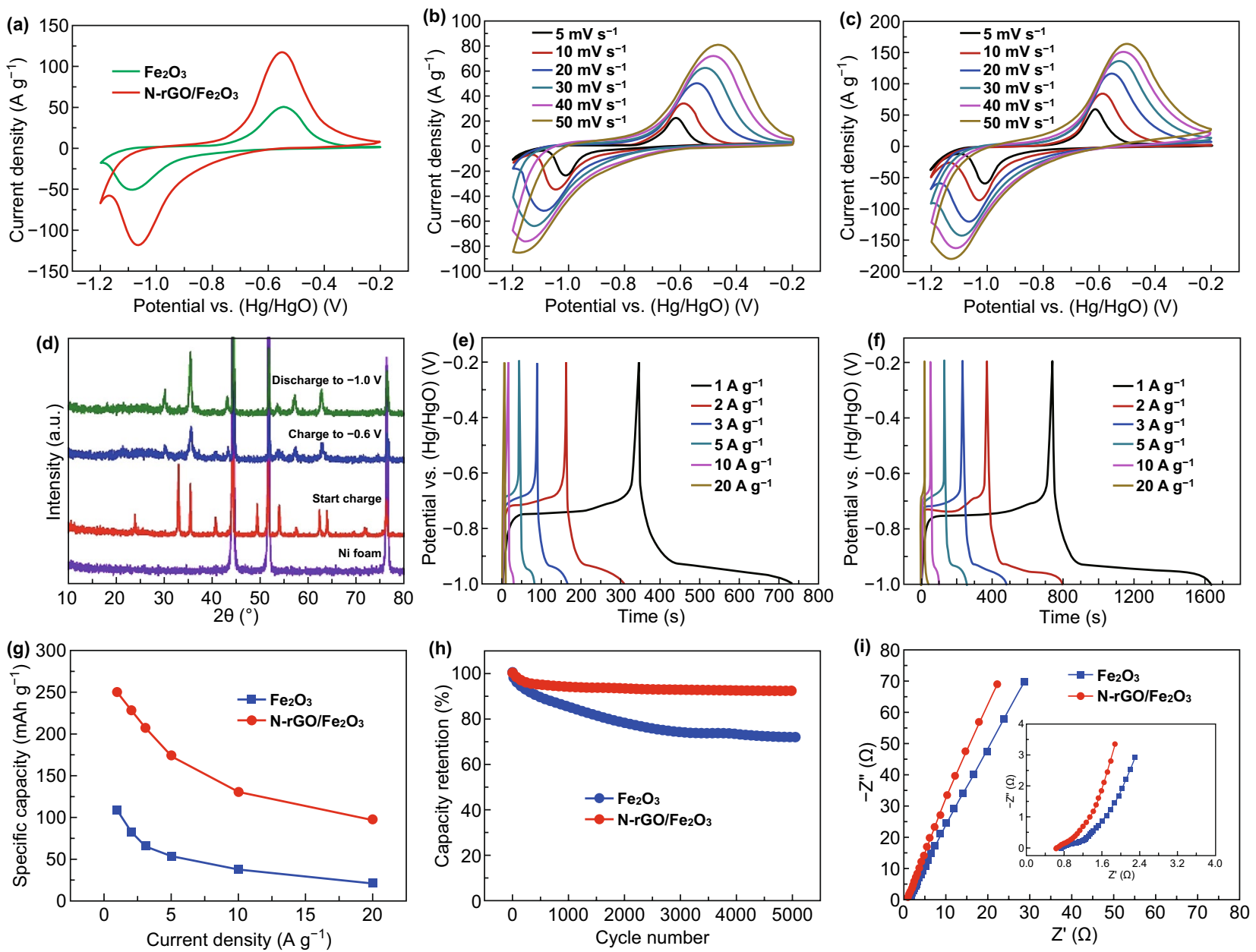

Fig. 7 a Comparison of $\mathrm{CV}$ curves of the pristine $\mathrm{Fe}_{2} \mathrm{O}_{3}$ and $\mathrm{N}-\mathrm{rGO} / \mathrm{Fe}_{2} \mathrm{O}_{3}$ electrodes at $20 \mathrm{mV} \mathrm{s}$. $\mathrm{CV}$ curves at various scan rates of the b pristine $\mathrm{Fe}_{2} \mathrm{O}_{3}$ and $\mathbf{c} \mathrm{N}-\mathrm{rGO} / \mathrm{Fe}_{2} \mathrm{O}_{3}$ electrodes. d Ex-situ XRD measurement of the $\mathrm{N}-\mathrm{rGO} / \mathrm{Fe}_{2} \mathrm{O}_{3}$ electrode during different electrochemical steps. GCD curves at various current densities of the e pristine $\mathrm{Fe}_{2} \mathrm{O}_{3}$ and $\mathbf{f} \mathrm{N}-\mathrm{rGO} / \mathrm{Fe}_{2} \mathrm{O}_{3}$ electrodes. $\mathbf{g}$ The rate performances, $\mathbf{h}$ cycling performances, and $\mathbf{i}$ EIS plots of the pristine $\mathrm{Fe}_{2} \mathrm{O}_{3}$ and $\mathrm{N}-\mathrm{rGO} / \mathrm{Fe}_{2} \mathrm{O}_{3}$ electrodes

materials reported in the literature [56-58, 60-64]. The cycle property of the $\mathrm{Fe}_{2} \mathrm{O}_{3}$ and $\mathrm{N}-\mathrm{rGO} / \mathrm{Fe}_{2} \mathrm{O}_{3}$ electrodes was further compared by the repeated GCD tests at 3 $\mathrm{A} \mathrm{g}^{-1}$ over 5000 cycles, as manifested in Fig. 7h. The $\mathrm{N}-\mathrm{rGO} / \mathrm{Fe}_{2} \mathrm{O}_{3}$ electrode manifests a better cycle stability with $92.1 \%$ capacity retention than that of the $\mathrm{Fe}_{2} \mathrm{O}_{3}$ electrode $(71.8 \%)$ after 5000 cycles, suggesting that the unique N-rGO-tightly-wrapped $\mathrm{Fe}_{2} \mathrm{O}_{3}$ composite structure can prevent the agglomeration of $\mathrm{Fe}_{2} \mathrm{O}_{3}$ and N-rGO and alleviate the volume change in the repeated charging-discharging processes, leading to the improvement of cycle performance. Moreover, the EIS measurement was taken, and the Nyquist plots are demonstrated in Fig. 7i. The N-rGO/ $/ \mathrm{Fe}_{2} \mathrm{O}_{3}$ electrode shows smaller intercept and semicircle diameter in the high-frequency region as well as higher slope value in the low-frequency region than those of the $\mathrm{Fe}_{2} \mathrm{O}_{3}$ electrode. Therefore, the results well demonstrate why the $\mathrm{N}-\mathrm{rGO} / \mathrm{Fe}_{2} \mathrm{O}_{3}$ electrode presents improved electrochemical performances in comparison with the $\mathrm{Fe}_{2} \mathrm{O}_{3}$ electrode.

\subsection{Electrochemical Characterizations of the $\mathrm{N}, \mathrm{S}-\mathrm{CQDs} / \mathrm{NiCo}_{2} \mathrm{~S}_{4} / / \mathrm{N}-\mathrm{rGO} / \mathrm{Fe}_{2} \mathrm{O}_{3}$ Alkaline Aqueous Battery}

To further clarify the superior electrochemical properties of the $\mathrm{N}, \mathrm{S}-\mathrm{CQD} / \mathrm{NiCo}_{2} \mathrm{~S}_{4}$ and $\mathrm{N}-\mathrm{rGO} / \mathrm{Fe}_{2} \mathrm{O}_{3}$ composites, a novel alkaline aqueous battery was assembled by, respectively, employing the two composites as the cathode and 

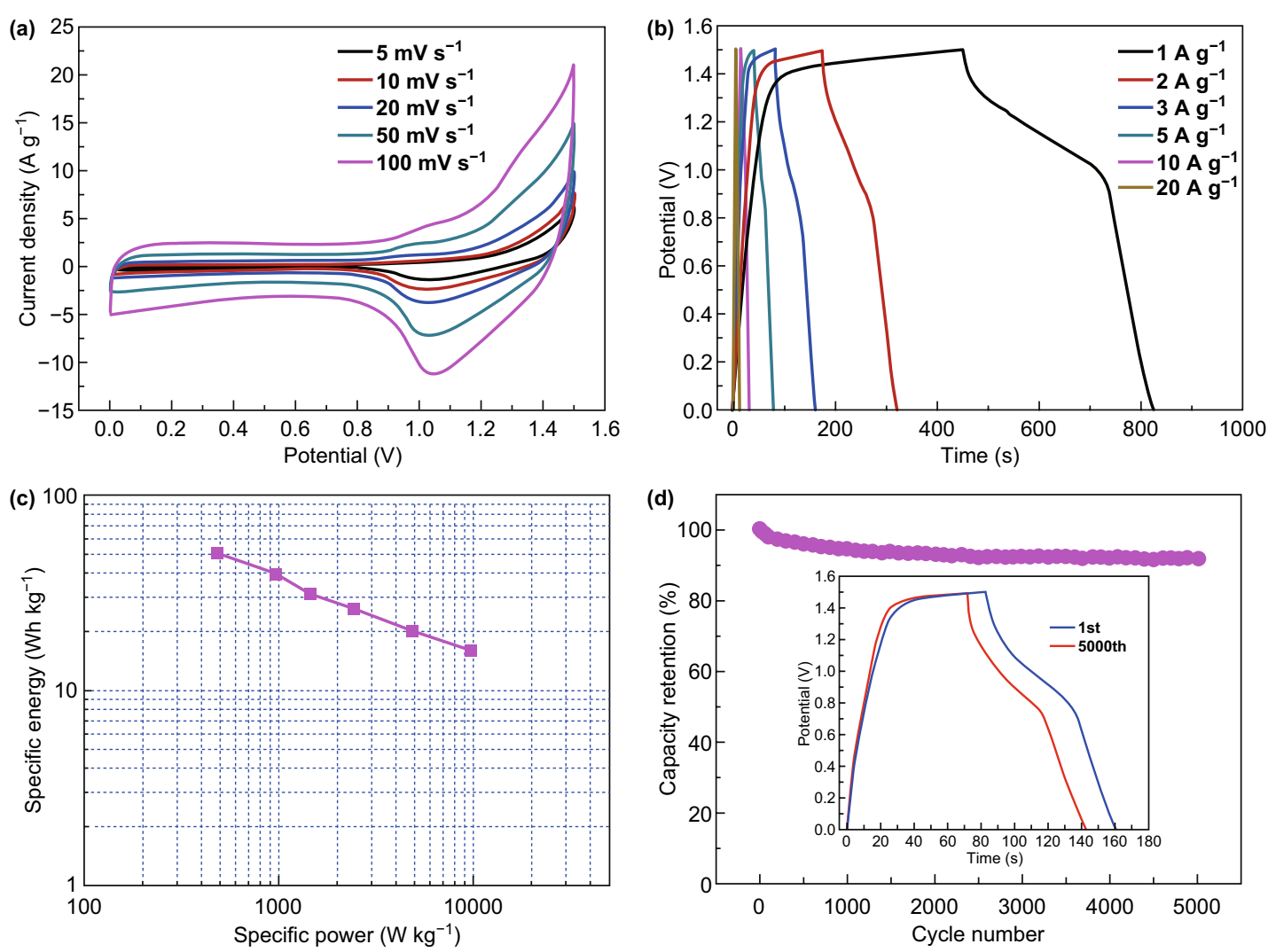

Fig. 8 a CV curves, b GCD curves, $\mathbf{c}$ Ragone plots and $\mathbf{d}$ cycling performance of the N,S-CQDs/ $\mathrm{NiCo}_{2} \mathrm{~S}_{4} / / \mathrm{N}-\mathrm{rGO} / \mathrm{Fe}_{2} \mathrm{O}_{3} \mathrm{device}$

anode, and the electrochemical performances, including CV, GCD and EIS, were tested in a voltage window of $0-1.5 \mathrm{~V}$ with $2 \mathrm{M} \mathrm{KOH}$ solution as electrolyte. Figure 8a displays the $\mathrm{CV}$ curves of the as-obtained alkaline aqueous battery at scan rates ranging from 5 to $100 \mathrm{mV} \mathrm{s}^{-1}$, and the shape of $\mathrm{CV}$ curves indicates that the capacity originates from the combined contribution of both Faradaic redox reaction and capacitive EDLC at all scan rates. The GCD curves of the alkaline aqueous battery at current densities of 1-20 A $\mathrm{g}^{-1}$ are presented in Fig. 8b, and the as-obtained result is further employed to investigate the specific energy $(E)$ and specific power $(P)$ of the alkaline aqueous battery according to the following two formulas [10]: $E=0.5 C(\Delta V)^{2} / 3.6$ and $P=E / t$, where the $C, \Delta V$ and $t$ are, respectively, the specific capacity, voltage difference and discharge time of the alkaline aqueous battery. As demonstrated in Ragone plot of Fig. 8c, it is found that the alkaline aqueous battery delivers a superior specific energy of $50.2 \mathrm{Wh} \mathrm{kg}^{-1}$ at a specific power of $485 \mathrm{~W} \mathrm{~kg}^{-1}$ and still maintains a decent specific energy of $16.1 \mathrm{Wh} \mathrm{kg}^{-1}$ even at an ultrahigh specific power of $9.7 \mathrm{~kW} \mathrm{~kg}^{-1}$, implying the excellent power capability. Moreover, the highest specific energy of the assembled alkaline aqueous battery in our work is comparable to or even higher than that of alkaline aqueous devices reported in the literature, including $\mathrm{NiCo}_{2} \mathrm{O}_{4} / \mathrm{CQDs} / / \mathrm{AC}$ [10], $\mathrm{NiCo}_{2} \mathrm{~S}_{4} / \mathrm{NCF} / / \mathrm{OMC} / \mathrm{NCF}$ [32], Ni-Co-S/G//PCN [34], $\mathrm{CuCo}_{2} \mathrm{O}_{4} / \mathrm{CuO} / / \mathrm{Fe}_{2} \mathrm{O}_{3} / \mathrm{rGO}$ [56], $\mathrm{MnO}_{2} / \mathrm{FGS} / / \mathrm{Fe}_{2} \mathrm{O}_{3} /$ FGS [60], $\mathrm{Ni}(\mathrm{OH})_{2} / / \mathrm{AC}$ [65], $\mathrm{CF} / \mathrm{NiCo}_{2} \mathrm{~S}_{4} @ \mathrm{PPy} / / \mathrm{CF} / \mathrm{MoS}_{2}$ [66], NiCo $\mathrm{S}_{4} @ \mathrm{G} / / \mathrm{PC}$ [67], Ni-Co-S@G//RGH [68] and $\mathrm{MnO} / \mathrm{NCA} / / \mathrm{Fe}_{2} \mathrm{O}_{3} / \mathrm{NCA}$ [69]. Additionally, the cycling property of the as-obtained device demonstrated in Fig. 8d was estimated by the GCD measurements at $3 \mathrm{~A} \mathrm{~g}^{-1}$ over 5000 cycles, and $91.5 \%$ of capacity retention is maintained, suggesting the superior cycle stability.

The superior electrochemical properties of the N,S-CQDs/ $\mathrm{NiCo}_{2} \mathrm{~S}_{4} / / \mathrm{N}-\mathrm{rGO} / \mathrm{Fe}_{2} \mathrm{O}_{3}$ device are attributed to the following factors: (1) The utilization of CQDs as structure-directing agents induces the formation of unique $\mathrm{N}, \mathrm{S}$-codoped CQDs-decorated urchin-like nanorods-assembled $\mathrm{NiCo}_{2} \mathrm{~S}_{4}$ microspheres composite. The nanosized building blocks of the composite with a large surface area afford more efficient electroactive sites for charge storage, contributing to 
the enhanced specific capacity, and the micrometer-sized assemblies of the composite possess desirable and mechanical properties and superior structure stability, leading to the improved cycling life. Meanwhile, the utilization of CQDs as conductive agents, together with the N,S-codoped modification, greatly enhances the electronic conductivity of the composite, leading to the improvement of rate property; (2) the unique prism-like nanostructured $\mathrm{Fe}_{2} \mathrm{O}_{3}$ hexahedrons can provide sufficient surface active sites for redox reaction, giving rise to the enhanced specific capacity, and the conductive $\mathrm{N}$-rGO-decorated $\mathrm{Fe}_{2} \mathrm{O}_{3}$ can significantly boost the electrical conductivity of the composite anode materials, facilitating the fast electron transport kinetic and resulting in the enhanced rate property. Moreover, the $\mathrm{Fe}_{2} \mathrm{O}_{3}$ hexahedrons are tightly wrapped by the N-rGO layers, which effectively prevents the agglomeration and buffer against the volume change during the charging/discharging cycle process, substantially improving the cycling performance; (3) the ultrahigh-capacity $\mathrm{N}-\mathrm{rGO} / \mathrm{Fe}_{2} \mathrm{O}_{3}$ composite anode materials are utilized to couple with the high-performance $\mathrm{N}, \mathrm{S}-\mathrm{CQDs} / \mathrm{NiCo}_{2} \mathrm{~S}_{4}$ composite cathode materials to fabricate the alkaline aqueous battery, and the rational design and selection of cathode and anode materials render the resulting device achieve the enhanced specific energy, ultrahigh specific power and superior cycling life.

\section{Conclusions}

In a word, the graphitic CQDs are prepared via a scalable mixed-acid chemical oxidation method employing highly conductive and low-cost Super $\mathrm{P}$ powders as precursors, and the high yield of more than $50 \%$ is successfully acquired. Then, the resulting CQDs are further used as both structuredirecting and conductive agents to controllably synthesize the N,S-codoped CQDs-decorated urchin-like $\mathrm{NiCo}_{2} \mathrm{~S}_{4}$ composite microsphere cathode materials for the first time, which display evidently improved electrochemical properties including specific capacity, rate performance and cycle life benefited from the synergistic effect of highly conductive N, S-codoped CQDs and unique micro-/nanostructured $\mathrm{NiCo}_{2} \mathrm{~S}_{4}$ with Faradaic redox feature. Meanwhile, the N-rGO-wrapped prism-like $\mathrm{Fe}_{2} \mathrm{O}_{3}$ hexahedrons composite anode materials are prepared, which exhibit an ultrahigh specific capacity, substantially enhanced rate performance and cycle property due to the synergistic effect between highly conductive N-rGO and high-capacity nanostructured $\mathrm{Fe}_{2} \mathrm{O}_{3}$ hexahedrons. In view of their superior electrochemical properties and rational coupling of cathode and anode materials, a novel alkaline aqueous battery is assembled by employing $\mathrm{N}, \mathrm{S}-\mathrm{CQD} / \mathrm{NiCo}_{2} \mathrm{~S}_{4}$ as cathode and $\mathrm{N}-\mathrm{rGO} /$ $\mathrm{Fe}_{2} \mathrm{O}_{3}$ as anode in $2 \mathrm{M} \mathrm{KOH}$ aqueous electrolyte. The fabricated $\mathrm{N}, \mathrm{S}-\mathrm{CQD} / \mathrm{NiCo}_{2} \mathrm{~S}_{4} / / \mathrm{N}-\mathrm{rGO} / \mathrm{Fe}_{2} \mathrm{O}_{3}$ device delivers a high specific energy of $50.2 \mathrm{Wh} \mathrm{kg}^{-1}$ at a specific power of $485 \mathrm{~W} \mathrm{~kg}^{-1}$ or an ultrahigh specific power of $9.7 \mathrm{~kW} \mathrm{~kg}^{-1}$ at a decent specific energy of $16.1 \mathrm{Wh} \mathrm{kg}^{-1}$ and good cycling life with $91.5 \%$ of capacity retention at $3 \mathrm{~A} \mathrm{~g}^{-1}$ over 5,000 cycles. The present research gives a valuable reference for the design and exploitation of superior energy storage devices using battery/capacitive composite materials simultaneously as both cathode and anode in aqueous electrolyte.

Acknowledgments The work is financially supported by National Natural Science Foundation of China (21601057), Hunan Provincial Natural Science Foundation of China (2018JJ3116) and Excellent Youth Fund of Hunan Provincial Education Department (18B298).

Open Access This article is licensed under a Creative Commons Attribution 4.0 International License, which permits use, sharing, adaptation, distribution and reproduction in any medium or format, as long as you give appropriate credit to the original author(s) and the source, provide a link to the Creative Commons licence, and indicate if changes were made. The images or other third party material in this article are included in the article's Creative Commons licence, unless indicated otherwise in a credit line to the material. If material is not included in the article's Creative Commons licence and your intended use is not permitted by statutory regulation or exceeds the permitted use, you will need to obtain permission directly from the copyright holder. To view a copy of this licence, visit http://creativecommons.org/licenses/by/4.0/.

Electronic supplementary material The online version of this article (https://doi.org/10.1007/s40820-019-0355-0) contains supplementary material, which is available to authorized users.

\section{References}

1. S.Y. Lim, W. Shen, Z. Gao, Carbon quantum dots and their applications. Chem. Soc. Rev. 44, 362-381 (2015). https:// doi.org/10.1039/C4CS00269E

2. R. Das, R. Bandyopadhyay, P. Pramanik, Carbon quantum dots from natural resource: a review. Mater. Today Chem. 8, 96-109 (2018). https://doi.org/10.1016/j.mtche m.2018.03.003 
3. J. Li, X. Yun, Z. Hu, L. Xi, N. Li, H. Tang, P. Lu, Y. Zhu, Three-dimensional nitrogen and phosphorus co-doped carbon quantum dots/reduced graphene oxide composite aerogels with a hierarchical porous structure as superior electrode materials for supercapacitors. J. Mater. Chem. A 7, 26311-26325 (2019). https://doi.org/10.1039/C9TA08151H

4. X.T. Zheng, A. Ananthanarayanan, K.Q. Luo, P. Chen, Glowing graphene quantum dots and carbon dots: properties, syntheses, and biological applications. Small 11, 16201636 (2015). https://doi.org/10.1002/smll.201402648

5. X. Li, M. Rui, J. Song, Z. Shen, H. Zeng, Carbon and graphene quantum dots for optoelectronic and energy devices: a review. Adv. Funct. Mater. 25, 4929-4947 (2015). https:// doi.org/10.1002/adfm.201501250

6. B. De, N. Karak, Recent progress in carbon dot-metal based nanohybrids for photochemical and electrochemical applications. J. Mater. Chem. A 5, 1826-1859 (2017). https://doi. org/10.1039/C6TA10220D

7. Y. Wang, A. Hu, Carbon quantum dots: synthesis, properties and applications. J. Mater. Chem. C 2, 6921-6939 (2014). https://doi.org/10.1039/C4TC00988F

8. Y. Zhu, X. Ji, C. Pan, Q. Sun, W. Song, L. Fang, Q. Chen, C.E. Banks, A carbon quantum dot decorated $\mathrm{RuO}_{2}$ network: outstanding supercapacitances under ultrafast charge and discharge. Energy Environ. Sci. 6, 3665-3675 (2013). https://doi. org/10.1039/C3EE41776J

9. J.-S. Wei, H. Ding, P. Zhang, Y.-F. Song, J. Chen, Y.-G. Wang, H.-M. Xiong, Carbon dots $/ \mathrm{NiCo}_{2} \mathrm{O}_{4}$ nanocomposites with various morphologies for high performance supercapacitors. Small 12, 5927-5934 (2016). https://doi.org/10.1002/ smll.201602164

10. Y. Zhu, Z. Wu, M. Jing, H. Hou, Y. Yang, Y. Zhang, X. Yang, W. Song, X. Jia, X. Ji, Porous $\mathrm{NiCo}_{2} \mathrm{O}_{4}$ spheres tuned through carbon quantum dots utilised as advanced materials for an asymmetric supercapacitor. J. Mater. Chem. A 3, 866-877 (2015). https://doi.org/10.1039/C4TA05507A

11. M.-S. Balogun, Y. Luo, F. Lyu, F. Wang, H. Yang, H. Li, C. Liang, M. Huang, Y. Huang, Y. Tong, Carbon quantum dot surface-engineered $\mathrm{VO}_{2}$ interwoven nanowires: a flexible cathode material for lithium and sodium ion batteries. ACS Appl. Mater. Interfaces 8, 9733-9744 (2016). https://doi. org/10.1021/acsami.6b01305

12. H. Hou, C.E. Banks, M. Jing, Y. Zhang, X. Ji, Carbon quantum dots and their derivative 3D porous carbon frameworks for sodium-ion batteries with ultralong cycle life. Adv. Mater. 27, 7861-7866 (2015). https://doi.org/10.1002/adma.201503816

13. C. Ma, K. Dai, H. Hou, X. Ji, L. Chen, D.G. Ivey, W. Wei, High ion-conducting solid-state composite electrolytes with carbon quantum dot nanofillers. Adv. Sci. 5, 1700996 (2018). https://doi.org/10.1002/advs.201700996

14. L. Zhang, Y. Yang, M.A. Ziaee, K. Lu, R. Wang, Nanohybrid of carbon quantum dots/molybdenum phosphide nanoparticle for efficient electrochemical hydrogen evolution in alkaline medium. ACS Appl. Mater. Interfaces 10, 9460-9467 (2018). https://doi.org/10.1021/acsami.8b00211
15. X. Xu, R. Ray, Y. Gu, H.J. Ploehn, L. Gearheart, K. Raker, W.A. Scrivens, Electrophoretic analysis and purification of fluorescent single-walled carbon nanotube fragments. J. Am. Chem. Soc. 126, 12736-12737 (2004). https://doi. org/10.1021/ja040082h

16. X. Yun, J. Li, X. Chen, H. Chen, L. Xiao, K. Xiang, W. Chen, H. Liao, Y. Zhu, Porous $\mathrm{Fe}_{2} \mathrm{O}_{3}$ modified by nitrogen-doped carbon quantum dots/reduced graphene oxide composite aerogel as a high-capacity and high-rate anode material for alkaline aqueous batteries. ACS Appl. Mater. Interfaces 11, 36970-36984 (2019). https://doi.org/10.1021/acsami.9b12827

17. Q. Liang, W. Ma, Y. Shi, Z. Li, X. Yang, Easy synthesis of highly fluorescent carbon quantum dots from gelatin and their luminescent properties and applications. Carbon 60, 421-428 (2013). https://doi.org/10.1016/j.carbon.2013.04.055

18. H. Peng, J. Travas-Sejdic, Simple aqueous solution route to luminescent carbogenic dots from carbohydrates. Chem. Mater. 21, 5563-5565 (2009). https://doi.org/10.1021/cm901 $593 y$

19. A.B. Bourlinos, A. Stassinopoulos, D. Anglos, R. Zboril, M. Karakassides, E.P. Giannelis, Surface functionalized carbogenic quantum dots. Small 4, 455-458 (2008). https://doi. org/10.1002/smll.200700578

20. R. Liu, D. Wu, S. Liu, K. Koynov, W. Knoll, Q. Li, An aqueous route to multicolor photoluminescent carbon dots using silica spheres as carriers. Angew. Chem. Int. Ed. 48, 4598-4601 (2009). https://doi.org/10.1002/anie.200900652

21. H. Zhu, X. Wang, Y. Li, Z. Wang, F. Yang, X. Yang, Microwave synthesis of fluorescent carbon nanoparticles with electrochemiluminescence properties. Chem. Commun. 34, 5118-5120 (2009). https://doi.org/10.1039/B907612C

22. X. Jia, X. Ji, Electrochemical probing of carbon quantum dots: not suitable for a single electrode material. RSC Adv. 5, 107270-107275 (2015). https://doi.org/10.1039/C5RA2 $4625 \mathrm{C}$

23. T.-Y. Wei, C.-H. Chen, H.-C. Chien, S.-Y. Lu, C.-C. Hu, A cost-effective supercapacitor material of ultrahigh specific capacitances: spinel nickel cobaltite aerogels from an epoxidedriven sol-gel process. Adv. Mater. 22, 347-351 (2010). https ://doi.org/10.1002/adma.200902175

24. G. He, M. Qiao, W. Li, Y. Lu, T. Zhao, R. Zou, B. Li, J.A. Darr, J. Hu, M.-M. Titirici, I.P. Parkin, S, N-Co-doped graphene-nickel cobalt sulfide aerogel: improved energy storage and electrocatalytic performance. Adv. Sci. 4, 1600214 (2017). https://doi.org/10.1002/advs.201600214

25. Y. Wang, Z. Chen, T. Lei, Y. Ai, Z. Peng, X. Yan, H. Li, J. Zhang, Z.M. Wang, Y.-L. Chueh, Hollow $\mathrm{NiCo}_{2} \mathrm{~S}_{4}$ nanospheres hybridized with $3 \mathrm{D}$ hierarchical porous $\mathrm{rGO} /$ $\mathrm{Fe}_{2} \mathrm{O}_{3}$ composites toward high-performance energy storage device. Adv. Energy Mater. 8, 1703453 (2018). https://doi. org/10.1002/aenm.201703453

26. W. Liu, H. Niu, J. Yang, K. Cheng, K. Ye, K. Zhu, G. Wang, D. Cao, J. Yan, Ternary transition metal sulfides embedded in graphene nanosheets as both the anode and cathode for high-performance asymmetric supercapacitors. Chem. Mater. 
30, 1055-1068 (2018). https://doi.org/10.1021/acs.chemm ater.7b04976

27. S. Tang, B. Zhu, X. Shi, J. Wu, X. Meng, General controlled sulfidation toward achieving novel nanosheet-built porous square-FeCo $\mathrm{S}_{4}$-tube arrays for high-performance asymmetric all-solid-state pseudocapacitors. Adv. Energy Mater. 7, 1601985 (2017). https://doi.org/10.1002/aenm.201601985

28. H. Khani, D.O. Wipf, Iron oxide nanosheets and pulse-electrodeposited $\mathrm{Ni}-\mathrm{Co}-\mathrm{S}$ nanoflake arrays for high-performance charge storage. ACS Appl. Mater. Interfaces 9, 6967-6978 (2017). https://doi.org/10.1021/acsami.6b11498

29. F. Lu, M. Zhou, W. Li, Q. Weng, C. Li, Y. Xue, X. Jiang, X. Zeng, Y. Bando, D. Golberg, Engineering sulfur vacancies and impurities in $\mathrm{NiCo}_{2} \mathrm{~S}_{4}$ nanostructures toward optimal supercapacitive performance. Nano Energy 26, 313-323 (2016). https ://doi.org/10.1016/j.nanoen.2016.05.042

30. B.Y. Guan, L. Yu, X. Wang, S. Song, X.W. Lou, Formation of onion-like $\mathrm{NiCo}_{2} \mathrm{~S}_{4}$ particles via sequential ion-exchange for hybrid supercapacitors. Adv. Mater. 29, 1605051 (2017). https ://doi.org/10.1002/adma.201605051

31. D. Bhattacharjya, A. Sinhamahapatra, J.-J. Ko, J.-S. Yu, High capacity and exceptional cycling stability of ternary metal sulfide nanorods as $\mathrm{Li}$ ion battery anodes. Chem. Commun. 51, 13350-13353 (2015). https://doi.org/10.1039/C5CC0 4289E

32. H. Li, G. Xu, J. Wang, L. Shen, H. Dou, X. Zhang, $\mathrm{NiCo}_{2} \mathrm{~S}_{4}$ nanosheets grown on nitrogen-doped carbon foams as an advanced electrode for supercapacitors. Adv. Energy Mater. 5, 1400977 (2015). https://doi.org/10.1002/aenm.201400977

33. Y. Cui, J. Zhang, C. Jin, Y. Liu, W. Luo, W. Zheng, Ionic liquid-controlled growth of $\mathrm{NiCo}_{2} \mathrm{~S}_{4} 3 \mathrm{D}$ hierarchical hollow nanoarrow arrays on $\mathrm{Ni}$ foam for superior performance binder free hybrid supercapacitors. Small 15, 1804318 (2019). https ://doi.org/10.1002/smll.201804318

34. J. Yang, C. Yu, X. Fan, S. Liang, S. Li, H. Huang, Z. Ling, C. Hao, J. Qiu, Electroactive edge site-enriched nickel-cobalt sulfide into graphene frameworks for high performance asymmetric supercapacitors. Energy Environ. Sci. 9, 1299-1307 (2016). https://doi.org/10.1039/C5EE03633J

35. D. Li, Y. Gong, C. Pan, Facile synthesis of hybrid CNTs/ $\mathrm{NiCo}_{2} \mathrm{~S}_{4}$ composite for high performance supercapacitors. Sci. Rep. 6, 29788 (2016). https://doi.org/10.1038/srep29788

36. J. Zhou, C. Booker, R. Li, X. Zhou, T.-K. Sham, X. Sun, Z. Ding, An electrochemical avenue to blue luminescent nanocrystals from multiwalled carbon nanotubes (MWCNTs). J. Am. Chem. Soc. 129, 744-745 (2007). https://doi. org/10.1021/ja0669070

37. Y. Dong, N. Zhou, X. Lin, J. Lin, Y. Chi, G. Chen, Extraction of electrochemiluminescent oxidized carbon quantum dots from activated carbon. Chem. Mater. 22, 5895-5899 (2010). https://doi.org/10.1021/cm1018844

38. F. Yuan, T. Yuan, L. Sui, Z. Wang, Z. Xi, Y. Li, X. Li, L. Fan, Z. Tan, A. Chen, M. Jin, S. Yang, Engineering triangular carbon quantum dots with unprecedented narrow bandwidth emission for multicolored LEDs. Nat. Commun. 9, 2249 (2018). https://doi.org/10.1038/s41467-018-04635-5
39. Y. Si, E.T. Samulski, Synthesis of water soluble graphene. Nano Lett. 8, 1679-1682 (2008). https://doi.org/10.1021/n1080 $604 \mathrm{~h}$

40. H. Li, X. He, Z. Kang, H. Huang, Y. Liu, J. Liu, S. Lian, C.H.A. Tsang, X. Yang, S.-T. Lee, Water-soluble fluorescent carbon quantum dots and photocatalyst design. Angew. Chem. Int. Ed. 49, 4430-4434 (2010). https://doi.org/10.1002/ anie. 200906154

41. C. Wei, Y. Huang, S. Xue, X. Zhang, X. Chen, J. Yan, W. Yao, One-step hydrothermal synthesis of flaky attached hollow-sphere structure $\mathrm{NiCo}_{2} \mathrm{~S}_{4}$ for electrochemical capacitor application. Chem. Eng. J. 317, 873-881 (2017). https://doi. org/10.1016/j.cej.2017.02.130

42. Q. Liu, J. Jin, J. Zhang, $\mathrm{NiCo}_{2} \mathrm{~S}_{4} @$ graphene as a bifunctional electrocatalyst for oxygen reduction and evolution reactions. ACS Appl. Mater. Interfaces 5, 5002-5008 (2013). https://doi. org/10.1021/am4007897

43. G. Qiuyue, X. Wang, Z. Shi, Z. Ye, W. Wang, N. Zhang, Z. Hong, M. Zhi, Synthesis of porous $\mathrm{NiCo}_{2} \mathrm{~S}_{4}$ aerogel for supercapacitor electrode and oxygen evolution reaction electrocatalyst. Chem. Eng. J. 331, 185-193 (2018). https://doi. org/10.1016/j.cej.2017.08.067

44. D. Yuan, G. Huang, D. Yin, X. Wang, C. Wang, L. Wang, Metal-organic framework template synthesis of $\mathrm{NiCo}_{2} \mathrm{~S}_{4} @ \mathrm{C}$ encapsulated in hollow nitrogen-doped carbon cubes with enhanced electrochemical performance for lithium storage. ACS Appl. Mater. Interfaces 9, 18178-18186 (2017). https ://doi.org/10.1021/acsami.7b02176

45. S. Li, P. Ge, F. Jiang, H. Shuai, W. Xu, Y. Jiang, Y. Zhang, J. Hu, H. Hou, X. Ji, The advance of nickel-cobalt-sulfide as ultra-fast/high sodium storage materials: the influences of morphology structure, phase evolution and interface property. Energy Storage Mater. 16, 267-280 (2019). https://doi. org/10.1016/j.ensm.2018.06.006

46. Y. Zheng, J. Xu, X. Yang, Y. Zhang, Y. Shang, X. Hu, Decoration $\mathrm{NiCo}_{2} \mathrm{~S}_{4}$ nanoflakes onto Ppy nanotubes as core-shell heterostructure material for high-performance asymmetric supercapacitor. Chem. Eng. J. 333, 111-121 (2018). https:// doi.org/10.1016/j.cej.2017.09.155

47. S.N. Tiruneh, B.K. Kang, S.H. Kwag, Y. Lee, M. Kim, D.H. Yoon, Synergistically active $\mathrm{NiCo}_{2} \mathrm{~S}_{4}$ nanoparticles coupled with holey defect graphene hydrogel for high-performance solid-state supercapacitors. Chem. Eur. J. 24, 1-9 (2018). https://doi.org/10.1002/chem.201705445

48. R. Jia, F. Zhu, S. Sun, T. Zhai, H. Xia, Dual support ensuring high-energy supercapacitors via high-performance $\mathrm{NiCo}_{2} \mathrm{~S}_{4} @ \mathrm{Fe}_{2} \mathrm{O}_{3}$ anode and working potential enlarged $\mathrm{MnO}_{2}$ cathode. J. Power Sources 341, 427-434 (2017). https ://doi.org/10.1016/j.jpowsour.2016.12.014

49. B. Li, Z. Tian, H. Li, Z. Yang, Y. Wang, X. Wang, Self-supporting graphene aerogel electrode intensified by $\mathrm{NiCo}_{2} \mathrm{~S}_{4}$ nanoparticles for asymmetric supercapacitor. Electrochim. Acta 314, 32-39 (2019). https://doi.org/10.1016/j.elect acta.2019.05.040

50. Y. Zhu, X. Ji, Z. Wu, Y. Liu, $\mathrm{NiCo}_{2} \mathrm{~S}_{4}$ hollow microsphere decorated by acetylene black for high-performance 
asymmetric supercapacitor. Electrochim. Acta 186, 562-571 (2015). https://doi.org/10.1016/j.electacta.2015.10.176

51. X. Liang, K. Nie, X. Ding, L. Dang, J. Sun et al., Highly compressible carbon sponge supercapacitor electrode with enhanced performance by growing nickel-cobalt sulfide nanosheets. ACS Appl. Mater. Interfaces 10, 10087-10095 (2018). https://doi.org/10.1021/acsami.7b19043

52. Y.-M. Fan, Y. Liu, X. Liu, Y. Liu, L.-Z. Fan, Hierarchical porous $\mathrm{NiCo}_{2} \mathrm{~S}_{4}$-rGO composites for high-performance supercapacitors. Electrochim. Acta 249, 1-8 (2017). https ://doi.org/10.1016/j.electacta.2017.07.175

53. Y. Shen, K. Zhang, B. Chen, F. Yang, K. Xu, X. Lu, Enhancing the electrochemical performance of nickel cobalt sulphides hollow nanospheres by structural modulation for asymmetric supercapacitors. J. Colloid Interf. Sci. 557, 135-143 (2019). https://doi.org/10.1016/j.jcis.2019.09.007

54. X. Yun, S. Wu, J. Li, L. Li, J. Zhou, P. Lu, H. Tang, Y. Zhu, Facile synthesis of crystalline $\mathrm{RuSe}_{2}$ nanoparticles as a novel pseudocapacitive electrode material for supercapacitors. Chem. Commun. 55, 12320-12323 (2019). https://doi. org/10.1039/c9cc06023e

55. Y. Zhu, Z. Huang, Z. Hu, L. Xi, X. Ji, Y. Liu, 3D Interconnected ultrathin cobalt selenide nanosheets as cathode materials for hybrid supercapacitors. Electrochim. Acta 269, 30-37 (2018). https://doi.org/10.1016/j.electacta.2018.02.146

56. Y. Wang, C. Shen, L. Niu, R. Li, H. Guo, Y. Shi, C. Li, X. Liu, Y. Gong, Hydrothermal synthesis of $\mathrm{CuCo}_{2} \mathrm{O}_{4} / \mathrm{CuO}$ nanowire arrays and $\mathrm{RGO} / \mathrm{Fe}_{2} \mathrm{O}_{3}$ composites for high-performance aqueous asymmetric supercapacitors. J. Mater. Chem. A 4, 9977-9985 (2016). https://doi.org/10.1039/C6TA02950G

57. Y. Li, J. Xu, T. Feng, Q. Yao, J. Xie, H. Xia, $\mathrm{Fe}_{2} \mathrm{O}_{3}$ nanoneedles on ultrafine nickel nanotube arrays as efficient anode for high-performance asymmetric supercapacitors. Adv. Funct. Mater. 27, 1606728 (2017). https://doi.org/10.1002/ adfm.201606728

58. L. Liu, J. Lang, P. Zhang, B. Hu, X. Yan, Facile synthesis of $\mathrm{Fe}_{2} \mathrm{O}_{3}$ nano-dots@ nitrogen-doped graphene for supercapacitor electrode with ultralong cycle life in $\mathrm{KOH}$ electrolyte. ACS Appl. Mater. Interfaces 8, 9335-9344 (2016). https://doi. org/10.1021/acsami.6b00225

59. F. Yang, T. Qiu, C. Chi, S. Liang, L. Deng, X. Wang, C. Wang, J. Fu, Y. Wang, Y. Li, Synergistic effects of nitrogen-doped graphene and $\mathrm{Fe}_{2} \mathrm{O}_{3}$ nanocomposites in catalytic oxidization of aldehyde with $\mathrm{O}_{2}$. Chem. Eng. J. 330, 880-889 (2017). https ://doi.org/10.1016/j.cej.2017.08.022

60. H. Xia, C. Hong, B. Li, B. Zhao, Z. Lin, M. Zheng, S.V. Savilov, S.M. Aldoshin, Facile synthesis of hematite quantumdot/functionalized graphene-sheet composites as advanced anode materials for asymmetric supercapacitors. Adv.
Funct. Mater. 25, 627-635 (2015). https://doi.org/10.1002/ adfm.201403554

61. Y. Zhu, S. Cheng, W. Zhou, J. Jia, L. Yang, M. Yao, M. Wang, J. Zhou, P. Wu, M. Liu, Construction and performance characterization of $\alpha-\mathrm{Fe}_{2} \mathrm{O}_{3} / \mathrm{rGO}$ composite for long-cycling-life supercapacitor anode. ACS Sustainable Chem. Eng. 5, 50675074 (2017). https://doi.org/10.1021/acssuschemeng.7b00445

62. Q.X. Low, G.W. Ho, Facile structural tuning and compositing of iron oxide-graphene anode towards enhanced supacapacitive performance. Nano Energy 5, 28-35 (2014). https://doi. org/10.1016/j.nanoen.2014.01.002

63. X. Xu, W. Shi, P. Li, S. Ye, C. Ye, H. Ye, T. Lu, A. Zheng, J. Zhu, L. Xu, M. Zhong, X. Cao, Facile fabrication of threedimensional graphene and metal-organic framework composites and their derivatives for flexible all-solid-state supercapacitors. Chem. Mater. 29, 6058-6065 (2017). https://doi. org/10.1021/acs.chemmater.7b01947

64. Y. Zeng, Y. Han, Y. Zhao, Y. Zeng, M. Yu, Y. Liu, H. Tang, Y. Tong, X. Lu, Advanced Ti-doped $\mathrm{Fe}_{2} \mathrm{O}_{3} @$ PEDOT core/ shell anode for high-energy asymmetric supercapacitors. Adv. Energy Mater. 5, 1402176 (2015). https://doi.org/10.1002/ aenm.201402176

65. H.B. Li, M.H. Yu, F.X. Wang, P. Liu, Y. Liang et al., Amorphous nickel hydroxide nanospheres with ultrahigh capacitance and energy density as electrochemical pseudocapacitor materials. Nat. Commun. 4, 1894 (2013). https://doi. org/10.1038/ncomms 2932

66. J. Huang, J. Wei, Y. Xu, Y. Xiao, Y. Chen, A pinecone-inspired hierarchical vertically aligned nanosheet array electrode for high-performance asymmetric supercapacitors. J. Mater. Chem. A 5, 23349-23360 (2017). https://doi.org/10.1039/ C7TA07868D

67. F. Yu, Z. Chang, X. Yuan, F. Wang, Y. Zhu et al., Ultrathin $\mathrm{NiCo}_{2} \mathrm{~S}_{4} @$ graphene with a core-shell structure as a high performance positive electrode for hybrid supercapacitors. J. Mater. Chem. A 6, 5856-5861 (2018). https://doi.org/10.1039/ C8TA00835C

68. X. Wang, S.-X. Zhao, L. Dong, Q.-L. Lu, J. Zhu, C.-W. Nan, One-step synthesis of surface-enriched nickel cobalt sulfide nanoparticles on graphene for high-performance supercapacitors. Energy Storage Mater. 6, 180-187 (2017). https://doi. org/10.1016/j.ensm.2016.11.005

69. G. Sun, H. Xie, J. Ran, L. Ma, X. Shen, J. Hu, H. Tong, Rational design of uniformly embedded metal oxide nanoparticles into nitrogen-doped carbon aerogel for high-performance asymmetric supercapacitors with a high operating voltage window. J. Mater. Chem. A 4, 16576-16587 (2016). https://doi.org/10.1039/C6TA07240B 